\title{
Sludge Mass Reduction: Primary Compositional Factors that Influence Melt Rate for Future Sludge Batch Projections
}

\author{
J.D. Newell \\ D.H. Miller \\ M.E. Stone \\ B.R. Pickenheim
}

August 2008

Environmental \& Chemical Process Technology Savannah River National Laboratory 
SRNS-STI-2008-00081

Revision 0

\section{DISCLAIMER}

This work was prepared under an agreement with and funded by the U.S. Government. Neither the U.S. Government or its employees, nor any of its contractors, subcontractors or their employees, makes any express or implied: 1. warranty or assumes any legal liability for the accuracy, completeness, or for the use or results of such use of any information, product, or process disclosed; or 2. representation that such use or results of such use would not infringe privately owned rights; or 3. endorsement or recommendation of any specifically identified commercial product, process, or service. Any views and opinions of authors expressed in this work do not necessarily state or reflect those of the United States Government, or its contractors, or subcontractors.

This document was prepared in conjunction with work accomplished under Contract No. DE-AC09-08SR22470 with the U.S. Department of Energy. 
Keywords: sludge mass reduction, DWPF, Al

Dissolution, melt rate, $M R F$

Retention: permanent

\title{
Factors that Influence Melt Rate for Future Sludge Batch Projections
}

\author{
J.D. Newell \\ D.H. Miller \\ M.E. Stone \\ B.R. Pickenheim
}

August 2008

Environmental \& Chemical Process Technology Savannah River National Laboratory 


\section{REVIEWS AND APPROVALS}

\section{AUTHORS:}

J.D. Newell, Process Engineering Technology

Date

D.H. Miller, Process Engineering Technology

Date

M.E. Stone, Process Engineering Technology

Date

B.R. Pickenheim, Process Engineering Technology

Date

TECHNICAL REVIEWER:

D.K. Peeler, Process Engineering Technology

Date

\section{APPROVERS:}

C.C. Herman, Manager, Process Engineering Technology Group

Date

J.C. Griffin, Manager, E\&CPT Research Programs

Date

M.T. Keefer, Project Owner - Sludge Mass Reduction Program

Date

Technology Development and Tank Closure - Liquid Waste Organization

P.C. Suggs, DOE - SRS/AMWDP

Date

Technology Development Lead 


\section{EXECUTIVE SUMMARY}

The Savannah River National Laboratory (SRNL) was tasked to provide an assessment of the downstream impacts to the Defense Waste Processing Facility (DWPF) of decisions regarding the implementation of Al-dissolution to support sludge mass reduction and processing. Based on future sludge batch compositional projections from the Liquid Waste Organization's (LWO) sludge batch plan, assessments have been made with respect to the ability to maintain comparable projected operating windows for sludges with and without Al-dissolution. As part of that previous assessment, candidate frits were identified to provide insight into melt rate for average sludge batches representing with and without Al-dissolution flowsheets.

Initial melt rate studies using the melt rate furnace (MRF) were performed using five frits each for Cluster 2 and Cluster 4 compositions representing average without and with Al-dissolution. It was determined, however, that the REDOX endpoint $\left(\mathrm{Fe}^{2+} / \Sigma \mathrm{Fe}\right.$ for the glass) for Clusters 2 and 4 resulted in an overly oxidized feed which negatively affected the initial melt rate tests. After the sludge was adjusted to a more reduced state, additional testing was performed with frits that contained both high and low concentrations of sodium and boron oxides. These frits were selected strictly based on the ability to ascertain compositional trends in melt rate and did not necessarily apply to any acceptability criteria for DWPF processing. The melt rate data are in general agreement with historical trends observed at SRNL and during processing of SB3 (Sludge Batch 3)and SB4 in DWPF. When MAR acceptability criteria were applied, Frit 510 was seen to have the highest melt rate at $0.67 \mathrm{in} / \mathrm{hr}$ for Cluster 2 (without Al-dissolution), which is compositionally similar to SB4. For Cluster 4 (with Al-dissolution), which is compositionally similar to SB3, Frit 418 had the highest melt rate at $0.63 \mathrm{in} / \mathrm{hr}$. Based on this data, there appears to be a slight advantage of the Frit 510 based system without Al-dissolution relative to the Frit 418 based system with Al-dissolution.

Though the without aluminum dissolution scenario suggests a slightly higher melt rate with frit 510, several points must be taken into consideration:

1. The MRF does not have the ability to assess liquid feeds and, thus, rheology impacts. Instead, the MRF is a "static" test bed in which a mass of dried melter feed (SRAT product plus frit) is placed in an "isothermal" furnace for a period of time to assess melt rate. These conditions, although historically effective in terms of identifying candidate frits for specific sludge batches and mapping out melt rate versus waste loading trends, do not allow for assessments of the potential impact of feed rheology on melt rate. That is, if the rheological properties of the slurried melter feed resulted in the mounding of the feed in the melter (i.e., the melter feed was thick and did not flow across the cold cap), melt rate and/or melter operations (i.e., surges) could be negatively impacted. This could affect one or both flowsheets.

2. Waste throughput factors were not determined for Frit 510 and Frit 418 over multiple waste loadings. In order to provide insight into the mission life versus canister count question, one needs to define the maximum waste throughput for both flowsheets. Due to funding limitations, the melt rate testing only evaluated melt rate at a fixed waste loading.

3. DWPF will be processing SB5 through their facility in mid-November 2008. Insight into the over arching questions of melt rate, waste throughput, and mission life can be obtained directly from the facility. It is recommended that processing of SB5 through the facility be monitored closely and that data be used as input into the 
SRNS-STI-2008-00081

Revision 0

decision making process on whether to implement Al-dissolution for future sludge batches. 


\section{TABLE OF CONTENTS}

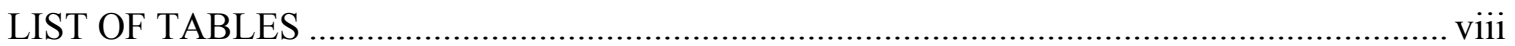

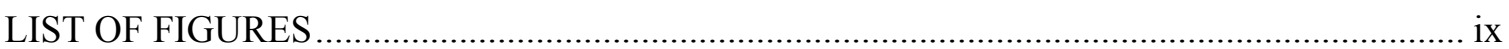

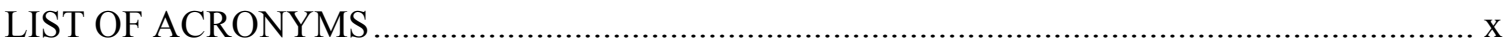

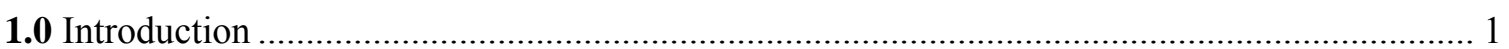

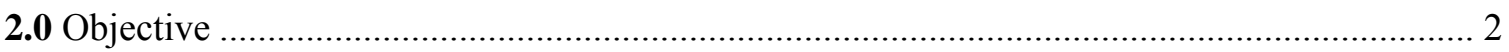

3.0 Background: Historical Trends of Melt Rate and Waste Loading .......................................... 2

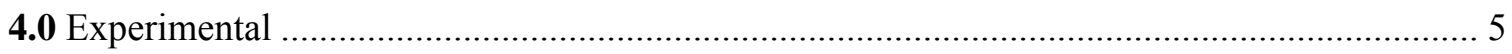

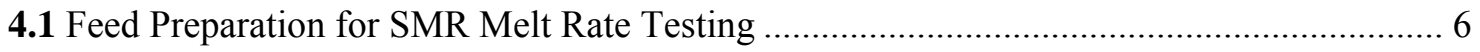

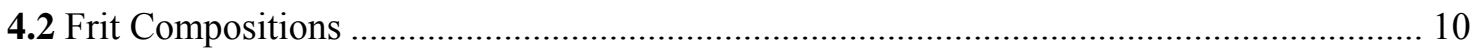

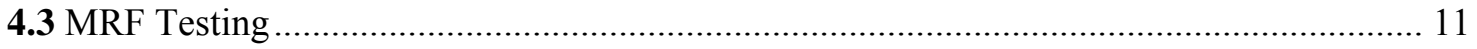

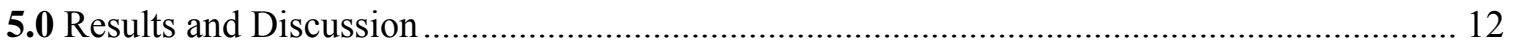

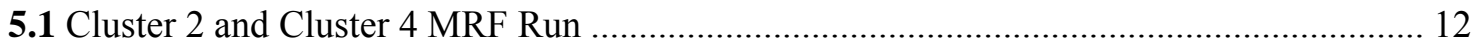

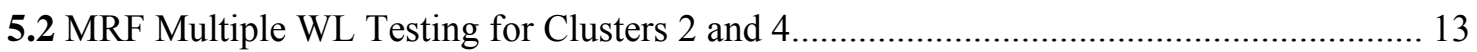

5.3 REDOX

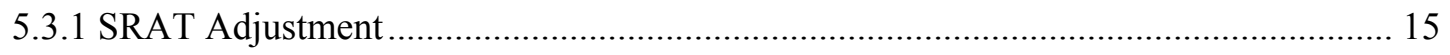

5.4 Additional MRF Runs with the "REDOX" Adjusted SRAT Products ................................ 16

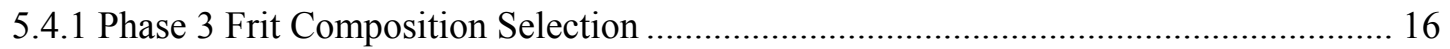

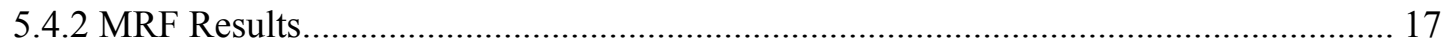

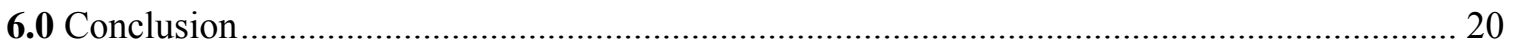

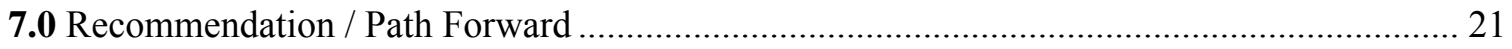

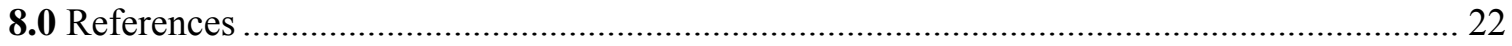

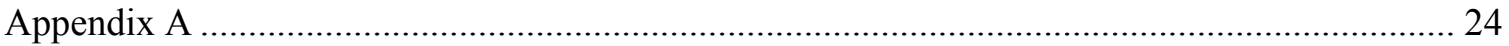




\section{LIST OF TABLES}

Table 4-1: Projected and Normalized Elemental Compositions.................................................. 6

Table 4-2: Simulant Elemental Composition Results................................................................... 7

Table 4-3: Simulant Anion Composition and Solids Results ...................................................... 7

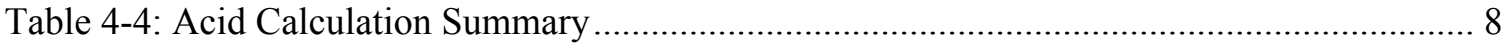

Table 4-5: Target versus Measured SRAT Product Elemental Oxides ....................................... 9

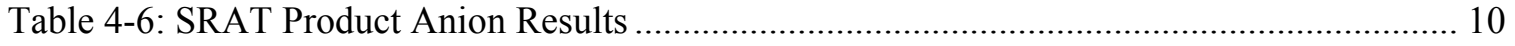

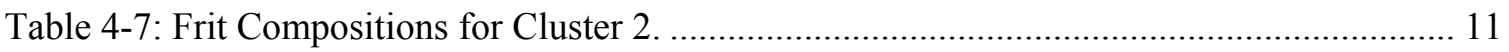

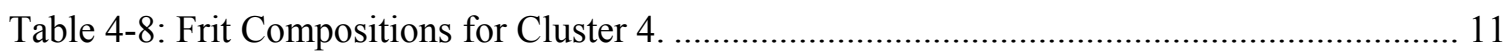

Table 5-1: MRF Test Results for Cluster 2 (w/o Aluminum Dissolution) .................................... 12

Table 5-2: MRF Test Results for Cluster 4 (with Aluminum Dissolution) .................................. 12

Table 5-3: SMR Frit Compositions (wt.\%) for Each Sludge Batch Cluster.................................. 13

Table 5-4: SMR MRF Multiple Waste Loading Results for Clusters 2 and 4 ........................... 13

Table 5-5: Initial REDOX values for Clusters 2 and 4 SRAT products..................................... 15

Table 5-6: Final REDOX values for Clusters 2 and 4 SRAT products ........................................ 16

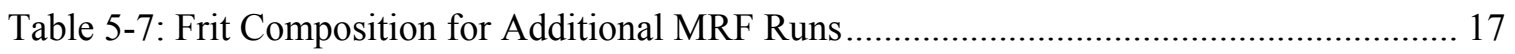

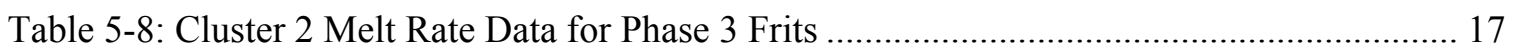

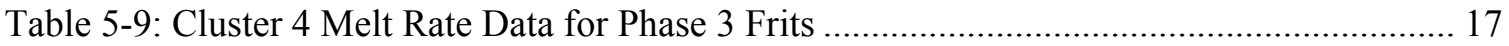




\section{LIST OF FIGURES}

Figure 3-1: Historical Trend Between Melt Rate and Waste Loading........................................ 3

Figure 3-2. Schematic in which Higher WT for "Without Al-Dissolution" .................................. 4

Figure 3-3. Schematic in which Higher WT for "Without Al-Dissolution" .................................... 4

Figure 5-1: Comparison of WTF and MR with respect to WL for Cluster 2 .............................. 14

Figure 5-2: Comparison of WTF and MR with respect to WL for Cluster 4 .............................. 14

Figure 5-3: Graphical Representation of Cluster 4 Melt Rate Data for All Phase 3 Frits (MAR

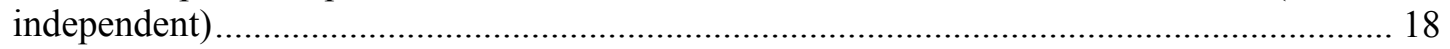

Figure 5-4: Melt Rate for Clusters 2 and 4 with Respect to Sodium Concentration ..................... 19

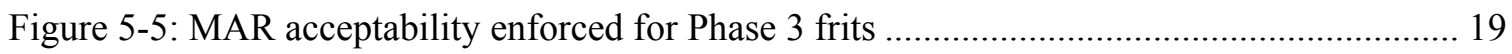




\section{LIST OF ACRONYMS}

$\begin{array}{ll}\text { Al } & \text { Aluminum } \\ \text { CPC } & \text { Chemical Process Cell } \\ \text { DOE } & \text { Department of Energy } \\ \text { DWPF } & \text { Defense Waste Processing Facility } \\ \text { EM } & \text { Environmental Management } \\ \text { LMR } & \text { Linear Melt Rate } \\ \text { LTAD } & \text { Low Temperature Aluminum Dissolution } \\ \text { LWO } & \text { Liquid Waste Organization } \\ \text { MAR } & \text { Measurement Acceptability Region } \\ \text { MRF } & \text { Melt Rate Furnace } \\ \text { PCCS } & \text { Product Composition Control System } \\ \text { QA } & \text { Quality Assurance } \\ \text { SB } & \text { Sludge Batch } \\ \text { SMR } & \text { Sludge Mass Reduction } \\ \text { SRAT } & \text { Sludge Receipt and Adjustment Tank } \\ \text { SRNL } & \text { Savannah River National Laboratory } \\ \text { T } & \text { Liquidus Temperature } \\ \eta & \text { Viscosity } \\ \text { WALD } & \text { With Al-Dissolution } \\ \text { WL } & \text { Waste Loading (weight percent) } \\ \text { WOALD } & \text { Without Al-Dissolution } \\ \text { WT } & \text { Waste Throughput }\end{array}$




\subsection{Introduction}

Savannah River National Laboratory (SRNL) was tasked to provide an assessment of the potential downstream impacts to the Defense Waste Processing Facility (DWPF) of decisions concerning the implementation of Al-dissolution to support Sludge Mass Reduction (SMR). The primary intent of SMR is to minimize the mass of sludge that must be treated in DWPF via vitrification. Implementation of Al-dissolution is one means for accomplishing this objective since it should translate into a decrease in the number of high-level waste canisters produced assuming similar waste loadings can be achieved (as compared to the same sludge batch without Al-dissolution). However, there may be other technical issues that impact the effectiveness of the Al-dissolution process and decisions to implement. These include (but are not limited to):

(1) the effectiveness of the Al-dissolution process (i.e., the amount of Al that will be removed)[1],

(2) possible rheological issues associated with the sludge after Al-removal [2], which could hamper sludge transfer and/or melter processing and preparation in the Tank Farm,

(3) impacts to downstream processes [3] such as Saltstone (which will process the Al-rich supernate) and DWPF,

(4) impacts to glass formulation efforts (in particular, the ability of frit development efforts to compensate for the sludge compositional changes), and

(5) impacts to melt rate or waste throughput (i.e., the amount of waste being processed per unit time) for the DWPF.

If Al-dissolution is not implemented or less effective Al-dissolution is realized, glass formulation efforts will have to accommodate higher $\mathrm{Al}_{2} \mathrm{O}_{3}$ concentrations (assuming similar waste loadings are targeted). Although projected $\mathrm{Al}_{2} \mathrm{O}_{3}$ concentrations in glass do not appear to approach solubility limits for DWPF-type glasses [4], higher targeted waste loadings or significant improvements in melt rate would be required to off-set the increased sludge mass. It is possible that significant melt rate differences could exist between a sludge composition having undergone Al-dissolution relative to one that has not. A primary driver in defining that possible difference is the ability of frit development efforts to compensate for the higher or lower $\mathrm{Al}_{2} \mathrm{O}_{3}$ content while maintaining access to waste loadings of interest and meeting related process control criteria. As previously mentioned, the ability to target similar waste loadings for a sludge resulting from the Al-dissolution process, as compared to the same sludge without Al-dissolution, is the primary driver to support assessment of canister count differences.

Recently, the SRNL formulated a relatively high Al-based glass system for DWPF in support of Sludge Batch 4 (SB4) implementation.* As a result of that research, Frit 510 (a high $\mathrm{B}_{2} \mathrm{O}_{3}$-based frit) was recommended to DWPF. DWPF has been able to target a nominal waste loading of $34 \%$ for SB4 and, in general, glass production rates have not been limited by melt rate but by the ability to keep feed to the melter. SRNL has also been able to eliminate the formation of nepheline brought on by the high levels of both aluminum and sodium associated with HM feeds through the implementation of a nepheline discriminator and the use of the high $\mathrm{B}_{2} \mathrm{O}_{3}$-based Frit 510 .

Although processing of the relatively high $\mathrm{Al}_{2} \mathrm{O}_{3}$ based SB4 has been successful in DWPF, there is the potential to improve upon that flowsheet with the introduction of the Al-dissolution process

\footnotetext{
* It should be noted that even though SB4 was an $\mathrm{HM}$ based sludge (high $\mathrm{Al}_{2} \mathrm{O}_{3}$ ) without Al-dissolution, the $\mathrm{Al}_{2} \mathrm{O}_{3}$ concentrations are lower than those projected for SB5 with al-dissolution due to the SB3 PUREX (high $\mathrm{Fe}_{2} \mathrm{O}_{3}$ ) based heel blending affects.
} 
for future sludge batches. More specifically, if the Al-dissolution process can remove mass and minimize possible rheological effects on sludge transfer capabilities, while maintaining both waste loading targets and relatively high melt rates, not only will this have a direct impact on reducing canister count but will also maximize waste throughputs which lead to a positive impact of the overall mission life for DWPF.

Previous assessments have indicated that through strategic frit development efforts, it appears that similar projected operating windows can be achieved for sludges both with and without Aldissolution. Although this result suggests or supports the concept of minimizing canister counts for a specific sludge batch, the assessments did not evaluate or provide any insight into potential melt rate difference. The previous assessments did indicate that there may be more compositional flexibility in frit space for the without Al-dissolution flowsheet which raised a question on whether this would translate into higher melt rates for this flowsheet, which could lead to enhanced waste throughputs for DWPF [5].

The Department of Energy (DOE) - Office of Environmental Management (EM) has funded SRNL to assess the impacts of the Al-dissolution process on DWPF operations. As outlined in the Task Technical and Quality Assurance (QA) Plan [6], there are three major task activities associated with this program: (1) assessing projected operating windows for future sludge batches with and without high temperature Al-dissolution (which includes frit development efforts for higher $\mathrm{Al}_{2} \mathrm{O}_{3}$ based glasses), (2) evaluating melt rate for specific frit - sludge combinations of interest, and (3) addressing CPC (Chemical Process Cell) impacts. This report focuses on the impacts of the Al-dissolution process relative to melt rate. The impact on the projected operating windows and CPC processing were previously documented[5].

\subsection{Objective}

The objective of this task is to evaluate if significant melt rate differences could be realized for these two flowsheets (with and without Al-dissolution) based on strategic frit development selection. To support this task, "average" sludge compositions (referred to as Cluster 2 and Cluster 4) were developed based on future projections as defined in the current High Level Waste Systems plan [5].

\subsection{Background: Historical Trends of Melt Rate and Waste Loading}

Prior to a detailed discussion on the specific test and results of this study, a high level overview of the historical trends between melt rate and waste loading is warranted. The maximum waste throughput, amount of sludge processed per unit time, at DWPF is a function of several factors but two of the most critical are: waste loading and melt rate. The historical general trend between melt rate and WL indicates that as WL increases, melt rate gradually decreases, Figure 3-1. This trend leads to a situation in which the maximum waste throughput is not found at the maximum WL allowed by PCCS but at some intermediate WL determined experimentally or during DWPF operations. Therefore, if one were solely interested in minimizing the number of canisters produced, DWPF should target the maximum WL allowed by PCCS model predictions (with uncertainties accounted for). This would yield a minimum canister count. But based on previous operational metrics, this strategy could lead to a significant increase in canister pour times (or production rates), which ultimately could increase the overall mission life of both the tank farm and DWPF. 
As noted in Section 1.0, assuming mission life is a critical aspect or input into the Al-dissolution implementation decision, sole use of the MAR assessment results and the general comments about "comparable" operating windows with and without Al-dissolution could lead one to make a sub-optimal decision. More specifically, the MAR assessments provide no insight into melt rate and/or waste throughput. The MAR assessments provide the projected operating windows (as defined by PCCS acceptable waste loadings) over which the specific glass forming system could be processed. That being the case, if one were to take the projected operating windows from the previous report[5], an assessment of canister reduction counts could be made, however; no insight into the possible impacts on mission life would result.

Consider the two scenarios shown in Figure 3-2 and Figure 3-3 in which mission life is dependent upon the quantity of waste vitrified and waste throughput, which is a function of the melt rate versus waste loading curve. In Figure 3-2, the blue line represents a nominal waste throughput $(\mathrm{lb} / \mathrm{hr})$ for the without Al-dissolution flowsheet. The red line represents the with Al-dissolution flowsheet waste throughput. The difference in the amount of waste to be immobilized is strictly a function of the efficiency of the Al-dissolution process and the sludge batches to which it is applied. In this example, the waste throughput for the without Al-dissolution flowsheet is higher than the with Al-dissolution flowsheet (based on the slope) but not high enough to overcome the increased mass. Therefore, one could conclude that Al-dissolution would ultimately reduce overall mission life even though it has a lower waste throughput. This is an ideal situation given it could lead not only to a reduced mission life but a significant reduction in canister count.

Alternatively, consider the case in which the waste throughput for the without Al-dissolution flowsheet is substantially higher, Figure 3-3. Under this scenario, it could be possible that the higher waste throughput would overcome the mass differences between the two flowsheets resulting in a shorter mission life. Could this be the case given the MAR assessments (in general) provide more flexibility for frit development efforts to improve melt rate based strictly on the number of frits available to provide comparable operating windows? Another possible scenario could be if the Al-dissolution flowsheet had a negative impact on the rheology of the sludge which translated into significantly lower melt rates. These general type questions are a primary focus of the experimental melt rate portion of this program.

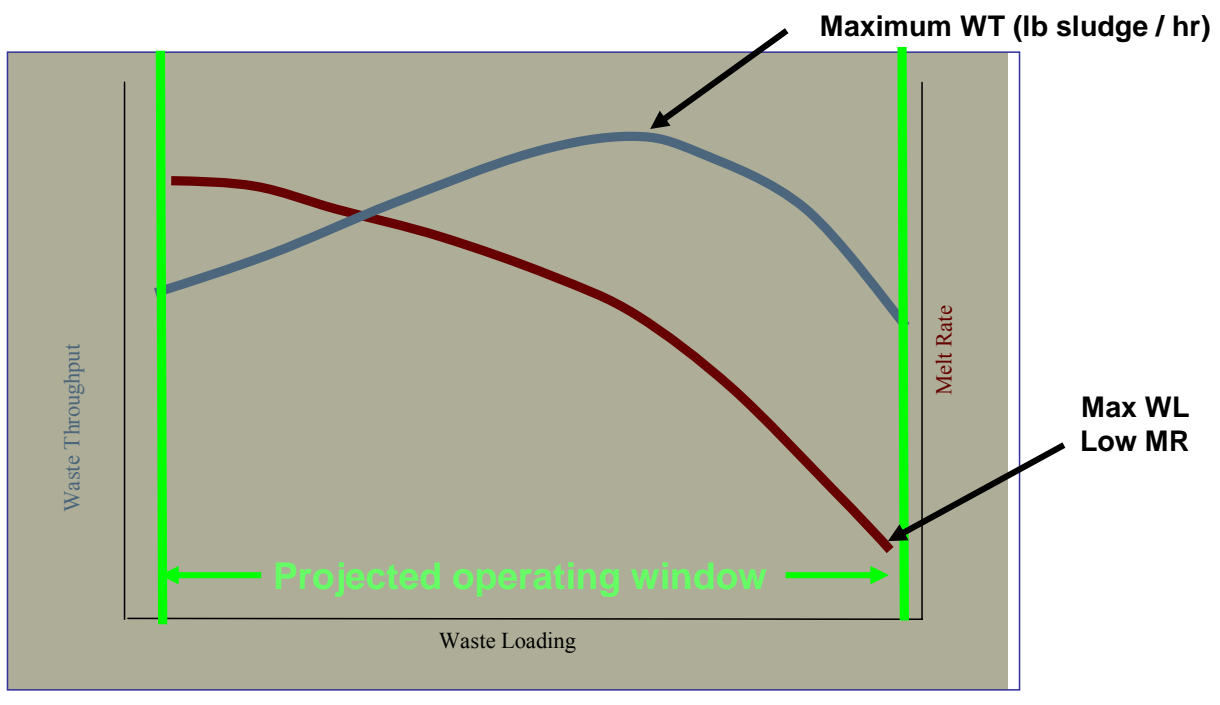

Figure 3-1: Historical Trend Between Melt Rate and Waste Loading. 


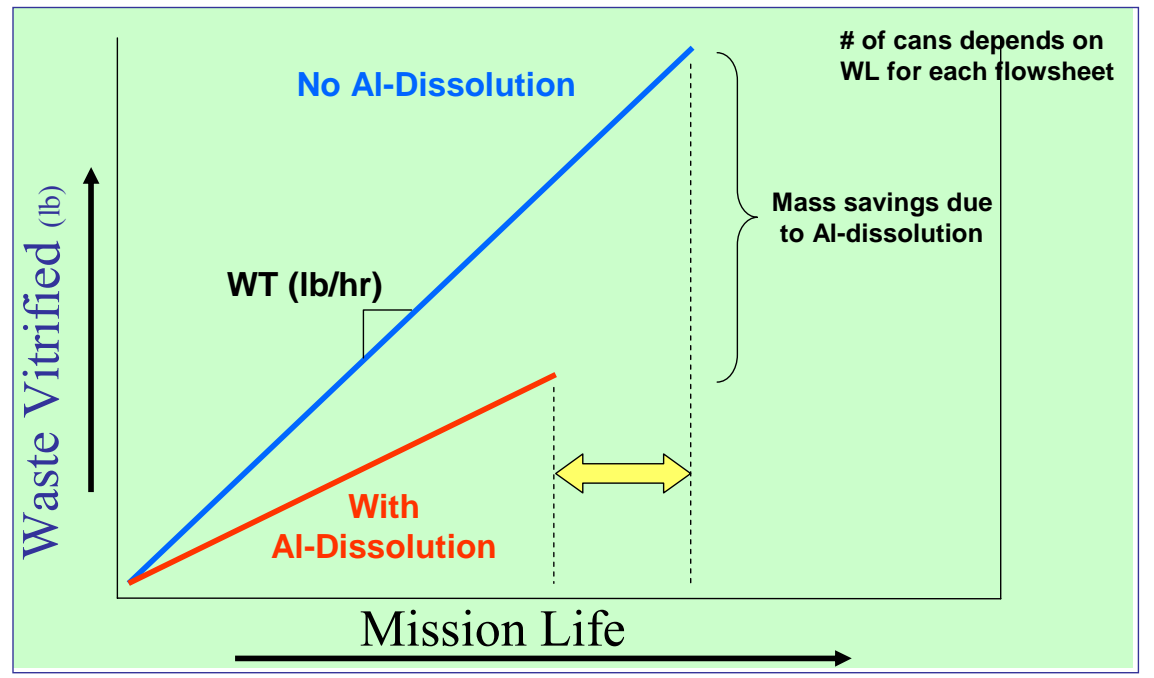

Figure 3-2. Schematic in which Higher WT for "Without Al-Dissolution" Does Not Overcome Mass Reduction in Terms of Mission Life.

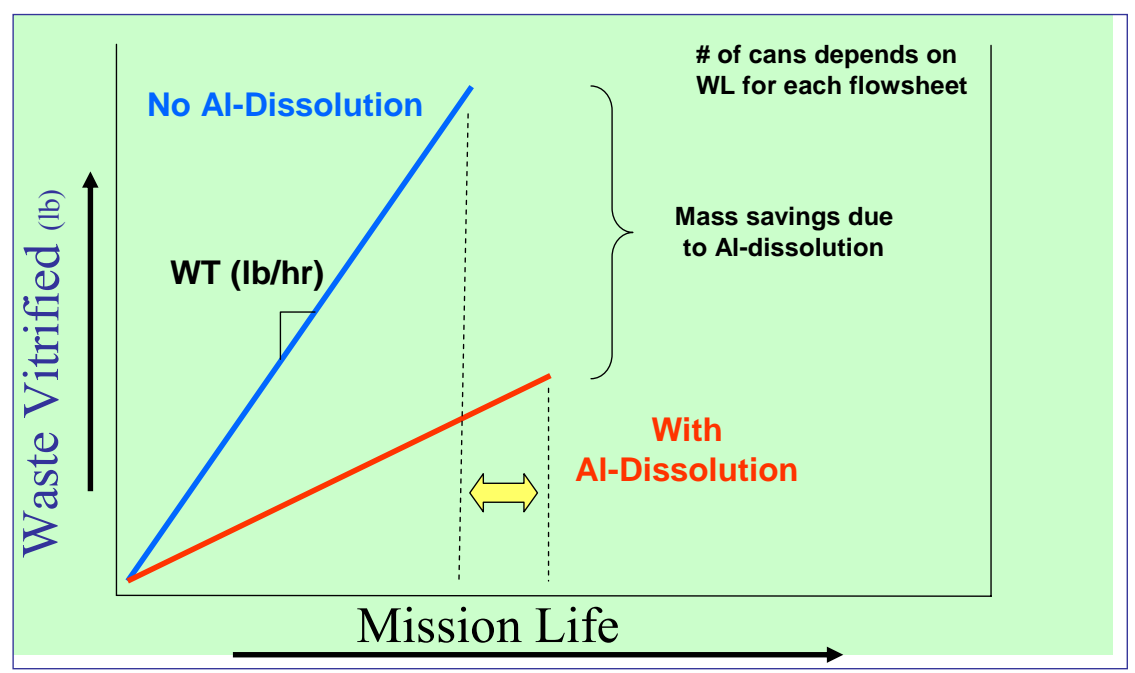

Figure 3-3. Schematic in which Higher WT for "Without Al-Dissolution" Does Overcome Mass Reduction in Terms of Mission Life. 
Recent DWPF processing could provide some insight into the potential throughput trends for high and low Al-based sludges. For example, consider DWPF operations for SB3 (Purex based feed, low $\mathrm{Al}_{2} \mathrm{O}_{3}$ and high $\mathrm{Na}_{2} \mathrm{O}$ ) and $\mathrm{SB} 4$ ( $\mathrm{HM}$ based feed, high $\left.\mathrm{Al}_{2} \mathrm{O}_{3}\right)$. Frit 418 was used as the primary frit to process SB3, which ultimately yielded a maximum waste throughput value of $\sim 55$ $\mathrm{lb} / \mathrm{hr}$ when targeting 38\% WL. Note the projected operating window for the Frit $418-\mathrm{SB} 3$ system was $\sim 25-45 \% \mathrm{WL}$, but lower melt rates were experienced at WLs greater than $38 \%$. Frit development for SB3 (leading to the Frit 418 recommendation) was primarily based on increasing the $\mathrm{Na}_{2} \mathrm{O}$ content of the frit to reduce liquidus temperature predictions and improve melt rate. Other frit components, $\mathrm{B}_{2} \mathrm{O}_{3}$ and $\mathrm{Li}_{2} \mathrm{O}$, did not have a significant impact on melt rate for that system.

Current processing of SB4 (HM based feed) is utilizing Frit 510 which is a high $\mathrm{B}_{2} \mathrm{O}_{3}$ based frit (14 wt\% relative to $8 \mathrm{wt} \%$ in Frit 418). Higher $\mathrm{B}_{2} \mathrm{O}_{3}$ concentrations were found during frit development efforts [7] to improve melt rate - with $\mathrm{Na}_{2} \mathrm{O}$ having less influence on melt rate than observed in the Frit 418 development for SB3. Although the current targeted WL for SB4 is 34\%, and the $\mathrm{wt} \%$ solids in the feed is relatively low due to pump in-leakage, waste throughputs are approximately $60-65 \mathrm{lb} / \mathrm{hr}$ with the CPC operations limiting production (prior to the decant of Tank 40). With indications that higher feed rates and/or higher WLs could be targeted, even greater waste throughputs could be achieved for this relatively high $\mathrm{Al}_{2} \mathrm{O}_{3}$ feed. Not knowing what WL will yield the maximum waste throughput for this system, the question one should ask is: Could the higher throughputs for this system overcome the same sludge (SB4) having undergone Al-dissolution, which may ultimately result in a sludge batch similar to SB3 (higher $\mathrm{Fe}_{2} \mathrm{O}_{3}$, lower $\mathrm{Al}_{2} \mathrm{O}_{3}$ )? More specifically, assume the maximum waste throughput for the Frit 510 - SB4 system was determined to be on the order of $80 \mathrm{lb} / \mathrm{hr}$. If LWO had implemented Aldissolution for SB4 (reducing the overall mass to be immobilized) but maximum waste throughput was similar to that observed for SB3 $(\sim 55 \mathrm{lb} / \mathrm{hr})$, which flowsheet would be completed first by DWPF (i.e., which flowsheet would have the minimum mission life impact)? Which flowsheet would yield the minimum number of canisters? Are the answers to these two questions the same? Even if the "without Al-dissolution" flowsheet did not fully reduce the overall mission life, are there other factors (e.g., implementation cost of Al-dissolution or rheology impacts) that would play a role in the decision making process?

Although experimentally determining the waste loading versus melt rate trends for each of the 26 future sludge batches provided by LWO would be of great value, time and budget constraints ultimately place restrictions on that possibility. Therefore, developing a defensible strategy that could be used to provide general insights into the advantages or impacts of Al-dissolution to overall mission life is paramount for this task. That is, how does one select a "worst case" or "best case" scenario for each flowsheet with respect to melt rate or waste throughput? Even if successful on that issue, how does one select the optimal frit to use in that melt rate assessment to provide each flowsheet with the best probability/possibility to show its optimal behavior? The frit selection strategy used to support initial melt rate testing for this program were discussed in detail in a previous report[5].

\subsection{Experimental}

In this section, specifics regarding the feed preparation for Cluster 2 and Cluster 4 Sludge Receipt and Adjustment Tank (SRAT) product are provided, fabrication and characterization of the frits used to support melt rate testing are discussed, and the experimental set-up and procedures used during the Melt Rate Furnace (MRF) tests summarized. 


\subsection{Feed Preparation for SMR Melt Rate Testing}

SRAT products for Cluster 2 (without Al-dissolution) and Cluster 4 (with Al-dissolution) were prepared from the compositions outlined in the initial Al-dissolution paper study[5] and represent average composition of future sludge batches for the without and with Al-dissolution flowsheet, respectively. Simulants were prepared and processed through the DWPF SRAT process to prepare SRAT product for melt rate testing..$^{\dagger}$ Compositions of the sludge simulants were renormalized after removal of radioactive species $\left(\mathrm{U}_{3} \mathrm{O}_{8}\right.$ and $\left.\mathrm{ThO}_{2}\right)$ from the elemental compositions and adjusted for charge balance as required. Elemental composition targets for each cluster simulant are shown in Table 4-1.

Table 4-1: Projected and Normalized Elemental Compositions

\begin{tabular}{|c|c|c|c|c|}
\hline & $\begin{array}{c}\text { Cluster } 2 \\
\text { Projection }\end{array}$ & $\begin{array}{c}\text { Cluster } 2 \\
\text { Normalized }\end{array}$ & $\begin{array}{c}\text { Cluster } 4 \\
\text { Projection }\end{array}$ & $\begin{array}{c}\text { Cluster } 4 \\
\text { Normalized }\end{array}$ \\
\hline & $\begin{array}{l}\text { Oxide } \\
\text { Wt \% }\end{array}$ & $\begin{array}{l}\text { Oxide } \\
\text { Wt \% }\end{array}$ & $\begin{array}{l}\text { Oxide } \\
\text { Wt \% }\end{array}$ & $\begin{array}{l}\text { Oxide } \\
\text { Wt \% }\end{array}$ \\
\hline $\mathrm{Al}_{2} \mathrm{O}_{3}$ & 23.10 & 25.23 & 14.62 & 15.89 \\
\hline $\mathrm{BaO}$ & 0.21 & 0.23 & 0.25 & 0.27 \\
\hline $\mathrm{CaO}$ & 2.63 & 2.87 & 3.26 & 3.54 \\
\hline $\mathrm{Ce}_{2} \mathrm{O}_{3}$ & 0.55 & 0.60 & 0.58 & 0.63 \\
\hline $\mathrm{Cr}_{2} \mathrm{O}_{3}$ & 0.27 & 0.29 & 0.34 & 0.37 \\
\hline $\mathrm{CuO}$ & 0.08 & 0.09 & 0.11 & 0.11 \\
\hline $\mathrm{Fe}_{2} \mathrm{O}_{3}$ & 30.81 & 33.66 & 35.17 & 38.24 \\
\hline $\mathrm{K} 2 \mathrm{O}$ & 0.18 & 0.19 & 0.23 & 0.24 \\
\hline $\mathrm{La}_{2} \mathrm{O}_{3}$ & 0.20 & 0.22 & 0.22 & 0.24 \\
\hline $\mathrm{MgO}$ & 0.41 & 0.45 & 0.47 & 0.51 \\
\hline $\mathrm{MnO}_{2}$ & 4.00 & 4.37 & 5.17 & 5.62 \\
\hline $\mathrm{Na}_{2} \mathrm{O}$ & 20.25 & 22.13 & 21.21 & 23.06 \\
\hline $\mathrm{NiO}$ & 1.16 & 1.27 & 1.28 & 1.39 \\
\hline $\mathrm{PbO}$ & 0.24 & 0.26 & 0.25 & 0.28 \\
\hline $\mathrm{SiO}_{2}$ & 3.35 & 3.66 & 5.09 & 5.54 \\
\hline $\mathrm{ThO}_{2}$ & 1.00 & - & 1.20 & - \\
\hline $\mathrm{TiO}_{2}$ & 3.29 & 3.60 & 2.77 & 3.01 \\
\hline $\mathrm{U}_{3} \mathrm{O}_{8}$ & 7.44 & - & 6.76 & - \\
\hline $\mathrm{ZnO}$ & 0.13 & 0.14 & 0.16 & 0.18 \\
\hline $\mathrm{ZrO}_{2}$ & 0.50 & 0.52 & 0.61 & 0.62 \\
\hline
\end{tabular}

Elemental compositions of each simulant were measured after preparation was complete. The compositions matched the targets for all major species, as shown in Table 4-2. The anion composition and solids results for each simulant are shown in Table 4-3.

\footnotetext{
$\dagger$ As will be mentioned in a following section, the MRF testing utilizes a dry SRAT product mixed with frit at some targeted WL for assessments of melt rate.
} 
Table 4-2: Simulant Elemental Composition Results

\begin{tabular}{|c|c|c|c|c|c|c|}
\hline & \multicolumn{3}{|c|}{ Cluster 2} & \multicolumn{3}{|c|}{ Cluster 4} \\
\hline & $\begin{array}{c}\text { Normalized } \\
\text { Oxide } \\
\text { Wt } \%\end{array}$ & $\begin{array}{l}\text { Result } \\
\text { Oxide } \\
\text { Wt \% }\end{array}$ & $\begin{array}{c}\% \\
\text { Difference }\end{array}$ & $\begin{array}{c}\text { Normalized } \\
\text { Oxide } \\
\text { Wt \% }\end{array}$ & $\begin{array}{l}\text { Result } \\
\text { Oxide } \\
\text { Wt \% }\end{array}$ & \% Difference \\
\hline $\mathrm{Al}_{2} \mathrm{O}_{3}$ & 25.23 & 27.88 & 10.49 & 15.89 & 18.03 & 13.47 \\
\hline $\mathrm{BaO}$ & 0.23 & 0.19 & -16.97 & 0.27 & 0.26 & -3.97 \\
\hline $\mathrm{CaO}$ & 2.87 & 3.09 & 7.56 & 3.54 & 3.96 & 11.72 \\
\hline $\mathrm{Ce}_{2} \mathrm{O}_{3}$ & 0.6 & 0.60 & 0.14 & 0.63 & 0.65 & 2.99 \\
\hline $\mathrm{Cr}_{2} \mathrm{O}_{3}$ & 0.29 & 0.24 & -16.93 & 0.37 & 0.33 & -9.84 \\
\hline $\mathrm{CuO}$ & 0.09 & 0.09 & 2.78 & 0.11 & 0.12 & 8.52 \\
\hline $\mathrm{Fe}_{2} \mathrm{O}_{3}$ & 33.66 & 33.82 & 0.47 & 38.24 & 39.11 & 2.28 \\
\hline $\mathrm{K}_{2} \mathrm{O}$ & 0.19 & 0.11 & -43.47 & 0.24 & 0.11 & -52.25 \\
\hline $\mathrm{La}_{2} \mathrm{O}_{3}$ & 0.22 & 0.00 & - & 0.24 & 0.00 & - \\
\hline $\mathrm{MgO}$ & 0.45 & 0.45 & -0.22 & 0.51 & 0.48 & -6.10 \\
\hline $\mathrm{MnO}_{2}$ & 4.37 & 4.25 & -2.74 & 5.62 & 5.44 & -3.15 \\
\hline $\mathrm{Na}_{2} \mathrm{O}$ & 22.13 & 18.29 & -17.34 & 23.06 & 18.63 & -19.21 \\
\hline $\mathrm{NiO}$ & 1.27 & 1.19 & -6.05 & 1.39 & 1.36 & -2.24 \\
\hline $\mathrm{PbO}$ & 0.26 & 0.19 & -25.02 & 0.28 & 0.20 & -27.49 \\
\hline $\mathrm{SiO}_{2}$ & 3.66 & 3.92 & 7.00 & 5.54 & 5.91 & 6.61 \\
\hline $\mathrm{TiO}_{2}$ & 3.6 & 3.82 & 6.00 & 3.01 & 3.15 & 4.58 \\
\hline $\mathrm{ZnO}$ & 0.14 & 0.13 & -6.11 & 0.18 & 0.18 & -1.49 \\
\hline $\mathrm{ZrO}_{2}$ & 0.52 & 0.30 & -41.46 & 0.62 & 0.27 & -55.80 \\
\hline
\end{tabular}

Table 4-3: Simulant Anion Composition and Solids Results

\begin{tabular}{|l|c|c|c|}
\hline & Cluster 2 & Cluster 4 & Units \\
\hline $\mathrm{F}$ & $<100$ & $<100$ & $\mathrm{mg} / \mathrm{kg}$ slurry \\
\hline $\mathrm{Cl}$ & $<100$ & $<100$ & $\mathrm{mg} / \mathrm{kg}$ slurry \\
\hline $\mathrm{NO}_{2}$ & 16700 & 14000 & $\mathrm{mg} / \mathrm{kg}$ slurry \\
\hline $\mathrm{NO}_{3}$ & 9870 & 9205 & $\mathrm{mg} / \mathrm{kg}$ slurry \\
\hline $\mathrm{SO}_{4}$ & 314 & 314 & $\mathrm{mg} / \mathrm{kg}$ slurry \\
\hline $\mathrm{PO}_{4}$ & $<100$ & $<100$ & $\mathrm{mg} / \mathrm{kg}$ slurry \\
\hline $\mathrm{HCO}_{2}$ & $<100$ & $<100$ & $\mathrm{mg} / \mathrm{kg}$ slurry \\
\hline $\mathrm{C}_{2} \mathrm{O}_{4}$ & 879 & 2845 & $\mathrm{mg} / \mathrm{kg}$ slurry \\
\hline $\mathrm{TIC}^{\mathrm{Base} \text { Eq. }}$ & 923 & 872 & $\mathrm{mg} / \mathrm{kg}$ slurry \\
\hline Total Solids & 22.85 & 22.55 & $\mathrm{molar}$ \\
\hline Soluble Solids & 6.65 & 6.61 & $\mathrm{wt} \%$ \\
\hline $\begin{array}{l}\text { Insoluble } \\
\text { Solids }\end{array}$ & 16.19 & 15.94 & $\mathrm{wt} \%$ \\
\hline Calcine Solids & 16.97 & 17.40 & $\mathrm{wt} \%$ \\
\hline
\end{tabular}


Four SRAT runs in the 22L SRAT vessels were performed to provide enough SRAT product to support the MRF tests - two SRAT runs with Cluster 2 and two SRAT runs with Cluster 4. The repeat runs were performed in the same vessels and no cleaning was performed between batches. The laboratory testing was conducted in accordance with procedure ITS-0094 of the L29 manual: "Laboratory Scale Chemical Process Cell Simulations". The experimental apparatus was set up using the guidance of SRNL-PSE-2006-00074 utilizing a 22L SRAT vessel. At the conclusion of the SRAT cycles, the SRAT products from the duplicate runs were blended and one $125 \mathrm{ml}$ sample was pulled from each of the blended SRAT products for analyses. All data was recorded in laboratory notebooks.

Mercury is not typically added to feed intended for use in melt rate testing to eliminate personnel exposure and avoid complicating the MRF testing set-up. Therefore, mercury was not added to either the Cluster 2 or Cluster 4 sludges. Noble metals were also excluded from these runs, a change from past protocols. Higher rates of formic acid destruction have been noted during melt rate testing without mercury than comparable runs with mercury during flowsheet evaluations. These higher destruction rates lead to melter feed with higher yield stress and less formate than comparable flowsheet runs. However, increased yield stress is not an issue here, as the SRAT product will be dried. Given the higher hydrogen generation rates seen with the higher formic acid destruction, adjusting the acid calculation to add more formic acid to account for the differences between the flowsheet runs and melt rate feed preparation runs was deemed less practical than eliminating the noble metals and adjusting the acid calculation for less formic acid destruction. The gas chromatograph analysis of the offgas is not needed for runs without noble metals, therefore the elimination of noble metals also represents a reduction in cost and complexity of the runs.

The standard acid calculations for CPC process simulations were completed based on the sample results from each run. The input assumptions, sample results utilized, and calculation results are shown in Appendix A. A summary of key assumptions and results is shown in Table 4-4.

Table 4-4: Acid Calculation Summary

\begin{tabular}{|c|c|c|c|}
\hline Results of Acid Calculation & Cluster 2 & Cluster4 & Units \\
\hline Stoichiometric factor & 130 & 130 & $\%$ \\
\hline Nitrite to Nitrate Conversion & 25 & 25 & $\%$ of nitrite in feed \\
\hline Formic Acid Destruction & 10 & 10 & $\begin{array}{c}\text { \% of formic acid } \\
\text { added }\end{array}$ \\
\hline Acid Addition Amount & 1.61 & 1.85 & g/mol per liter \\
\hline Ratio of Formic Acid to total Acid & 0.891 & 0.867 & $\begin{array}{l}\text { mol formic/mol } \\
\text { acid }\end{array}$ \\
\hline
\end{tabular}

The target versus measured elemental compositions for Cluster 2 and Cluster 4 SRAT products are shown in Table 4-5.

\footnotetext{
\$ Sludge Mass Reduction Notebook, WSRC-NB-2007-00173
} 
Table 4-5: Target versus Measured SRAT Product Elemental Oxides

\begin{tabular}{|c|c|c|c|c|}
\hline & $\begin{array}{c}\text { Cluster } 2 \\
\text { Target } \\
\text { Oxide } \\
\text { Wt \% } \\
\end{array}$ & $\begin{array}{c}\text { Cluster } 2 \\
\text { SRAT } \\
\text { Oxide } \\
\text { Wt \% } \\
\end{array}$ & $\begin{array}{c}\text { Cluster } 4 \\
\text { Target } \\
\text { Oxide } \\
\text { Wt \% } \\
\end{array}$ & $\begin{array}{c}\text { Cluster } 4 \\
\text { SRAT } \\
\text { Oxide } \\
\text { Wt \% } \\
\end{array}$ \\
\hline $\mathrm{Al}_{2} \mathrm{O}_{3}$ & 25.23 & 25.99 & 15.89 & 14.64 \\
\hline $\mathrm{BaO}$ & 0.23 & 0.19 & 0.27 & 0.23 \\
\hline $\mathrm{CaO}$ & 2.87 & 3.32 & 3.54 & 4.42 \\
\hline $\mathrm{Ce}_{2} \mathrm{O}_{3}$ & 0.60 & 0.58 & 0.63 & 0.56 \\
\hline $\mathrm{Cr}_{2} \mathrm{O}_{3}$ & 0.29 & 0.25 & 0.37 & 0.30 \\
\hline $\mathrm{CuO}$ & 0.09 & 0.09 & 0.11 & 0.10 \\
\hline $\mathrm{Fe}_{2} \mathrm{O}_{3}$ & 33.66 & 34.46 & 38.24 & 35.61 \\
\hline $\mathrm{K}_{2} \mathrm{O}$ & 0.19 & 0.14 & 0.24 & 0.16 \\
\hline $\mathrm{La}_{2} \mathrm{O}_{3}$ & 0.22 & $\mathrm{~nm}$ & 0.24 & $\mathrm{~nm}$ \\
\hline $\mathrm{MgO}$ & 0.45 & 0.49 & 0.51 & 0.60 \\
\hline $\mathrm{MnO}_{2}$ & 4.37 & 4.61 & 5.62 & 6.56 \\
\hline $\mathrm{Na}_{2} \mathrm{O}^{\S}$ & 22.13 & 21.26 & 23.06 & 25.99 \\
\hline $\mathrm{NiO}$ & 1.27 & 1.12 & 1.39 & 1.16 \\
\hline $\mathrm{PbO}$ & 0.26 & 0.17 & 0.28 & 0.08 \\
\hline $\mathrm{SiO}_{2}$ & 3.66 & 3.88 & 5.54 & 5.17 \\
\hline $\mathrm{ThO}_{2}$ & - & - & - & - \\
\hline $\mathrm{TiO}_{2}$ & 3.60 & 3.67 & 3.01 & 2.68 \\
\hline $\mathrm{U}_{3} \mathrm{O}_{8}$ & - & - & - & - \\
\hline $\mathrm{ZnO}$ & 0.14 & 0.13 & 0.18 & 0.16 \\
\hline $\mathrm{ZrO}_{2}$ & 0.52 & 0.31 & 0.62 & 0.23 \\
\hline
\end{tabular}

\footnotetext{
$\S \mathrm{Na}$ is likely biased high for Cluster 4 due to the low solids in the sample, as shown in the Table 4-6.
} 
Table 4-6: SRAT Product Anion Results

\begin{tabular}{|c|c|c|c|}
\hline & Cluster 2 & Cluster 4 & Units \\
\hline $\mathrm{F}$ & $<100$ & $<100$ & $\mathrm{mg} / \mathrm{kg}$ slurry \\
\hline $\mathrm{Cl}$ & 262 & 275 & $\mathrm{mg} / \mathrm{kg}$ slurry \\
\hline $\mathrm{NO}_{2}$ & 1310 & 531 & $\mathrm{mg} / \mathrm{kg}$ slurry \\
\hline $\mathrm{NO}_{3}$ & 22,250 & 24,350 & $\mathrm{mg} / \mathrm{kg}$ slurry \\
\hline $\mathrm{SO}_{4}$ & 175 & 185.5 & $\mathrm{mg} / \mathrm{kg}$ slurry \\
\hline $\mathrm{PO}_{4}$ & $<100$ & $<100$ & $\mathrm{mg} / \mathrm{kg}$ slurry \\
\hline $\mathrm{HCO}_{2}$ & 41,450 & 46,200 & $\mathrm{mg} / \mathrm{kg}$ slurry \\
\hline $\mathrm{C}_{2} \mathrm{O}_{4}$ & $<100$ & $<100$ & $\mathrm{mg} / \mathrm{kg}$ slurry \\
\hline Total Solids** & 21.88 & 19.66 & $w t \%$ \\
\hline Soluble Solids & 8.84 & 10.07 & $\mathrm{wt} \%$ \\
\hline $\begin{array}{l}\text { Insoluble } \\
\text { Solids }\end{array}$ & 13.04 & 9.59 & $\mathrm{wt} \%$ \\
\hline Calcine Solids & 14.03 & 12.11 & $\mathrm{wt} \%$ \\
\hline $\mathrm{pH}$ & 6.01 & 5.74 & \\
\hline Density & 1.13 & 1.14 & $\mathrm{~g} / \mathrm{ml}$ \\
\hline
\end{tabular}

The results indicate the feed preparation process produced feed that matched the desired elemental composition within measurement uncertainty. Nitrite destruction was not complete for some runs, but either met or was close to the DWPF limit of 1,000 ppm. See Appendix A for acid equation inputs and results.

\subsection{Frit Compositions}

Measurement Acceptability Region (MAR) assessments were completed for the Cluster 2 and Cluster 4 systems and were previously reported [5]. Glass compositional regions of interest were defined and evaluated against existing Product Composition Control System (PCCS) criteria to establish projected operating windows for each glass system.

With the end result being the investigation of melt rate on sludges containing either high or low concentrations of aluminum, frits were identified with compositions that would provide the best opportunities for influencing melt rate. Previous studies have shown that increasing $\mathrm{Na}_{2} \mathrm{O}$ content for SB3-type sludges (PUREX, high $\mathrm{Fe}_{2} \mathrm{O}_{3}$ ) provided an increase in melt rate[8]. For SB4-types ( $\mathrm{HM}$, high $\mathrm{Al}_{2} \mathrm{O}_{3}$ ), $\mathrm{Na}_{2} \mathrm{O}$ and $\mathrm{B}_{2} \mathrm{O}_{3}$ increases produced a positive effect on melt rate[9]. With this being considered, five frits were selected for each cluster, Table 4-7 and Table 4-8. All frits maintained a constant lithium concentration of $8 \mathrm{wt} \% . \quad \mathrm{Na}_{2} \mathrm{O}$ and $\mathrm{B}_{2} \mathrm{O}_{3}$ were varied from lower to higher concentrations in order to observe the effect in melt rates for each cluster.

Initially, five frits for each cluster were selected for testing. The frit selection was primarily based on the ability of the frit to satisfy all of the PCCS criteria at the MAR over a waste loading interval of interest to DWPF. Although this strategy identified specific frits of interest for Cluster 2 and Cluster 4, it did restrict the opportunity to increase certain frit oxide components to provide a more thorough assessment of historical trends. The five frits selected provided reasonable operating windows, were MAR acceptable, and to the extent possible provided primary frit

\footnotetext{
** Total and calcine solids were significantly low for the Cluster 4 samples. Repeat analysis was conducted that indicated total solids were $24.5 \mathrm{wt} \%$ for these samples and calcine solids was $16.4 \mathrm{wt} \%$. Cluster 2 also had lower solids, but the 23.9 and 16.0 values were closer to the original sample results.
} 
components to be tested over some range (albeit it rather limited). Based on the frit compositions, the melt rate data will provide little, if any, insight into the impacts of specific frit components on melt rate. More specifically, more than one component changes among the different frits selected for a specific cluster. Again, the initial strategy was to define the "optimal" frit available for use at DWPF - not to gain insight into specific compositional trends within each cluster.

Each frit was tested with its respective cluster at a fixed waste loading of $36 \%$ to identify a single frit for each cluster that yielded the maximum melt rate. Based on the results of the initial $36 \%$ WL MRF tests, it was postulated that a primary frit for each cluster would be identified and could be used to assess the impact of waste loading on melt rate. This would lead to or provide data to assess or at least get insight into the waste throughput curves for each cluster. This information could then be used to gage not only the impact on canister counts but also mission life for DWPF. Previous experience has shown if a frit performs better than another at one waste loading, it should do so at any given waste loading (i.e., the melt rate versus waste loading curves do not cross but are essentially parallel).

Table 4-7: Frit Compositions for Cluster 2.

\begin{tabular}{||l|c|c|c|c||}
\hline \hline Oxide & $\mathrm{B}_{2} \mathrm{O}_{3}$ & $\mathrm{Na}_{2} \mathrm{O}$ & $\mathrm{Li}_{2} \mathrm{O}$ & $\mathrm{SiO}_{2}$ \\
\hline SMR-1 & 8 & 11 & 8 & 73 \\
\hline SMR-2 & 11 & 9 & 8 & 72 \\
\hline SMR-3 & 14 & 7 & 8 & 71 \\
\hline SMR-4 & 17 & 5 & 8 & 70 \\
\hline SMR-5 & 9 & 8 & 8 & 75 \\
\hline
\end{tabular}

Table 4-8: Frit Compositions for Cluster 4.

\begin{tabular}{|l|c|c|c|c||}
\hline Oxide & $\mathrm{B}_{2} \mathrm{O}_{3}$ & $\mathrm{Na}_{2} \mathrm{O}$ & $\mathrm{Li}_{2} \mathrm{O}$ & $\mathrm{SiO}_{2}$ \\
\hline SMR-6 & 10 & 7 & 8 & 75 \\
\hline SMR-7 & 11 & 6 & 8 & 75 \\
\hline SMR-8 & 8 & 6 & 8 & 78 \\
\hline Frit 418 & 8 & 8 & 8 & 72 \\
\hline Frit 503 & 14 & 4 & 8 & 74 \\
\hline
\end{tabular}

\subsection{MRF Testing}

The dry-fed MRF has a cylindrical inner chamber that is approximately 0.5 cubic feet in size, with heating coils winding around the chamber walls. The diameter of the chamber is $\sim 7$ ", and an insulating sleeve and a $1200 \mathrm{~mL}$ stainless steel beaker (6" deep) were inserted from the top. The tests were conducted with the stainless steel beakers inserted with the sleeve so that the beaker bottom was approximately flush with the top of the uppermost chamber coil. An insulating block was used to cover the beaker. The furnace was heated to $1150^{\circ} \mathrm{C}$ with the top opening covered. Once the furnace reached the setpoint, the cover was removed and the beaker containing sufficient dried, sieved material to produce 525 grams of glass was inserted. After 50 minutes, the beaker was removed from the furnace and allowed to cool to room temperature. This residence time in the furnace was determined during testing in 2002 to establish a standard 
test time for melt rate comparison for this dry-fed furnace. After cooling down, the beakers were sectioned.

The relative melt rate is determined by measuring the height of the glass layer in the bottom of each sectioned beaker at 0.25 " intervals. The average height and duration in the furnace is used to yield a relative linear melt rate (LMR) number (inches/hour). General observations of the sectioned beaker are also used to describe differences between runs. Melt rate runs were performed under the auspices of a melt rate run plan [10]. MRF runs were performed at Aiken County Technology Laboratory for the selected frits for both clusters at a waste loading of $36 \%$. The results of all runs were recorded in notebook WSCR-NB-2003-00213.

\subsection{Results and Discussion}

\subsection{Cluster 2 and Cluster 4 MRF Run}

The results of the Cluster 2 (w/o Al-dissolution) MRF runs are summarized in Table 5-1. The melt rates are reported as LMR, inches of glass height produced per hour of melt time. As is common practice, a standard run was also made with Frit 418 without sludge. The standard melt rate was $1.33 \mathrm{in} / \mathrm{hr}$, which is consistent with the acceptable range of 1.3-1.6 in/hr.

Table 5-1: MRF Test Results for Cluster 2 (w/o Aluminum Dissolution)

\begin{tabular}{||c|c|c|c|c|c||}
\hline \hline Cluster & Frit & $\mathrm{B}_{2} \mathrm{O}_{3}$ & $\mathrm{Na}_{2} \mathrm{O}$ & $\mathrm{B}_{2} \mathrm{O}_{3}+\mathrm{Na}_{2} \mathrm{O}$ & LMR \\
\hline 2 & SMR-1 & 8 & 11 & 19 & 0.60 \\
\hline 2 & SMR-2 & 11 & 9 & 20 & 0.63 \\
\hline 2 & SMR-3 & 14 & 7 & 21 & 0.48 \\
\hline 2 & SMR-4 & 17 & 5 & 22 & 0.37 \\
\hline 2 & SMR-5 & 9 & 8 & 17 & 0.65 \\
\hline
\end{tabular}

With respect to composition, Cluster 2 (without Al-dissolution) is similar to SB4 (higher $\mathrm{Al}_{2} \mathrm{O}_{3}$ sludges). It was expected that the historical trends for $\mathrm{HM}$ feeds would hold true for Cluster 2 , namely higher concentrations of $\mathrm{B}_{2} \mathrm{O}_{3}$ and $\mathrm{Na}_{2} \mathrm{O}$ in the frit would result in higher melt rates. However, when the sum of the measured concentrations of the $\mathrm{Na}_{2} \mathrm{O}$ and $\mathrm{B}_{2} \mathrm{O}_{3}$ are examined with respect to melt rate, the opposite is generally observed.

The results of the Cluster 4 (with Al-dissolution) MRF run are summarized in Table 5-2. In general, the Cluster $4 \mathrm{MRF}$ data appears to follow the historical trend of higher melt rates for SB3-like systems (high $\mathrm{Fe}_{2} \mathrm{O}_{3}$ contents) by using frits with higher concentrations of $\mathrm{Na}_{2} \mathrm{O}$. The exception to the general trend is Frit 503 that targets a higher $\mathrm{B}_{2} \mathrm{O}_{3}$ content and relatively low $\mathrm{Na}_{2} \mathrm{O}$. It should be noted that the use of higher $\mathrm{B}_{2} \mathrm{O}_{3}$ based frit during the development of Frit 418 for SB3 was not extensive.

Table 5-2: MRF Test Results for Cluster 4 (with Aluminum Dissolution)

\begin{tabular}{||c|c|c|c|c|c||}
\hline \hline Cluster & Frit & $\mathrm{B}_{2} \mathrm{O}_{3}$ & $\mathrm{Na}_{2} \mathrm{O}$ & $\mathrm{B}_{2} \mathrm{O}_{3}+\mathrm{Na}_{2} \mathrm{O}$ & LMR \\
\hline 4 & SMR-6 & 10 & 7 & 17 & 0.52 \\
\hline 4 & SMR-7 & 11 & 6 & 17 & 0.39 \\
\hline 4 & SMR-8 & 8 & 6 & 14 & 0.43 \\
\hline 4 & 418 & 8 & 8 & 16 & 0.54 \\
\hline 4 & 503 & 14 & 4 & 18 & 0.57 \\
\hline
\end{tabular}


The Cluster 4 MRF data appears to follow the historical trend of higher melt rates for SB3-like systems (high $\mathrm{Fe}_{2} \mathrm{O}_{3}$ contents) by using frits with higher concentrations of $\mathrm{Na}_{2} \mathrm{O}$.

From the data presented in Table 5-1 and Table 5-2, the best linear melt rate for Cluster 2 (w/o Aluminum Dissolution) was achieved with Frit SMR-5 at 0.65 inches/hour. For Cluster 4 (with Aluminum Dissolution), the best linear melt rate was realized with Frit 503 at 0.57 inches/hour. Although these two frits were not the expected best performers based on historical melt rate trends, they were advanced to the second phase of the melt rate study: multiple WL testing. The intent of the Phase 2 testing was to assess the impact of WL on melt rate in an effort to get insight to any differences in waste throughput for the two specific glass systems of interest.

\subsection{MRF Multiple WL Testing for Clusters 2 and 4}

Based on the results of the initial 36\% waste loading tests, Frit SMR-5 and Frit 503 were chosen for multiple waste loading MRF tests for Cluster 2 and Cluster 4 respectively. Table 5-3 lists the compositions of the selected frits.

Table 5-3: SMR Frit Compositions (wt.\%) for Each Sludge Batch Cluster

\begin{tabular}{||c|c|c|c|c|c||}
\hline \hline Cluster & Frit & $\mathbf{B}_{\mathbf{2}} \mathbf{O}_{3}$ & $\mathbf{N a}_{\mathbf{2}} \mathbf{O}$ & $\mathbf{L i}_{\mathbf{2}} \mathbf{O}$ & $\mathbf{S i O}_{2}$ \\
\hline 2 & SMR-5 & 9 & 8 & 8 & 75 \\
\hline 4 & 503 & 14 & 4 & 8 & 74 \\
\hline
\end{tabular}

The results of the MRF multiple waste loading tests are presented in Table 5-4. Also shown in Table 5-4 is the waste throughput factor (WTF) which provides insight into the amount of waste processed per unit time - where WTF is determined by LMR x WL and is typically reported without units.

Table 5-4: SMR MRF Multiple Waste Loading Results for Clusters 2 and 4

\begin{tabular}{||c|c|c|c|c||}
\hline Cluster & Frit & WL & LMR (in/hr) & WTF \\
\hline 2 & SMR-5 & 32 & 0.65 & 20.8 \\
\hline 2 & SMR-5 & 34 & 0.70 & 23.8 \\
\hline 2 & SMR-5 & 36 & 0.71 & 25.6 \\
\hline 2 & SMR-5 & 38 & 0.67 & 25.5 \\
\hline 2 & SMR-5 & 40 & 0.59 & 23.6 \\
\hline 2 & SMR-5 & 42 & 0.61 & 25.6 \\
\hline & & & & \\
\hline 4 & 503 & 32 & 0.56 & 17.9 \\
\hline 4 & 503 & 34 & 0.59 & 20.1 \\
\hline 4 & 503 & 36 & 0.49 & 17.6 \\
\hline 4 & 503 & 38 & 0.50 & 19.0 \\
\hline 4 & 503 & 40 & 0.57 & 22.8 \\
\hline 4 & 503 & 42 & 0.53 & 22.3 \\
\hline
\end{tabular}

Some scatter in the WTF calculations exists since trends between waste loading and melt rate are inconsistent with previous observations. This can be seen graphically in Figure 5-1 and Figure 5-2 as compared to the historical trends (refer to Figure 1-1). In Figure 5-1 and Figure 5-2, waste throughput factors are seen by following the blue data points, while melt rate can be seen with the 
pink data points. Based on historical MRF data, waste throughput does not typically reverse trends as a function of increased waste loading (see Section 3.0 for more details), as seen in both figures. Historically, waste throughput typically is maximized at some intermediate waste loading. Having said that and based on the resulting data, the maximum WTF for the without Aldissolution Cluster 2 / SMR-5 feed was 25.6. The maximum WTF for the Al-dissolution Cluster 4 / Frit 503 feed was 22.8. Therefore, for this set of MRF tests, without Al-dissolution Cluster 2 feed had a WTF that was about $12 \%$ higher than Cluster 4 . This suggests that there is a possibility that the higher waste throughputs without Al-dissolution could off-set the lower mass to be vitrified with the Al-dissolution flowsheet.

\section{Figure 5-1: Comparison of WTF and MR with respect to WL for Cluster 2}

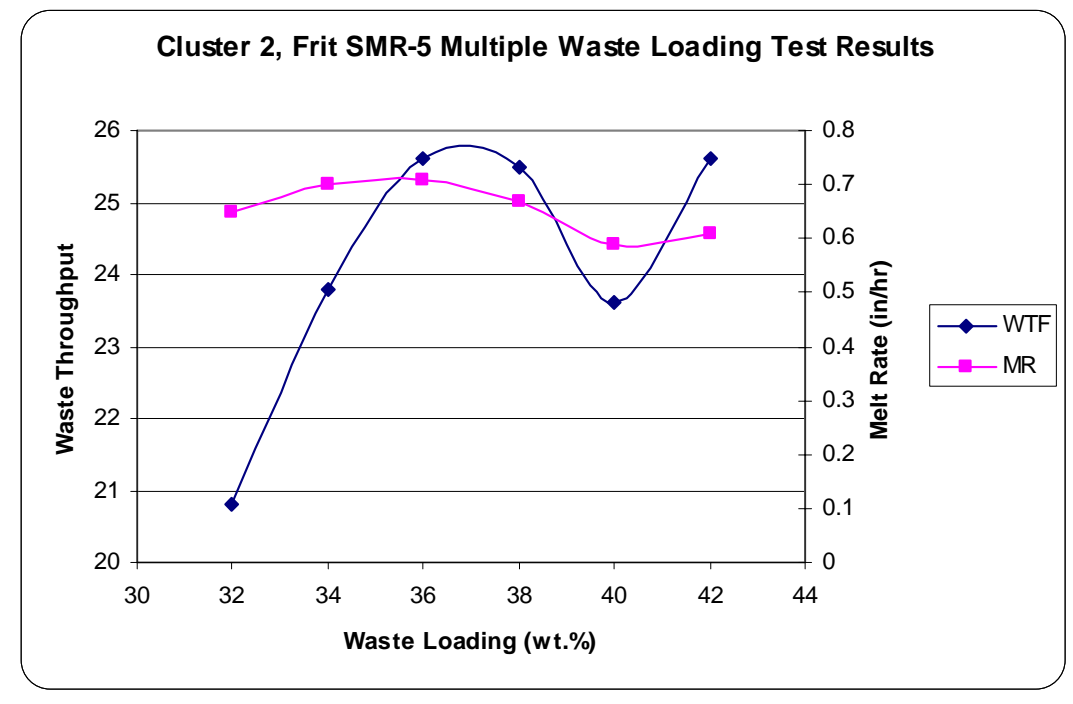

Figure 5-2: Comparison of WTF and MR with respect to WL for Cluster 4

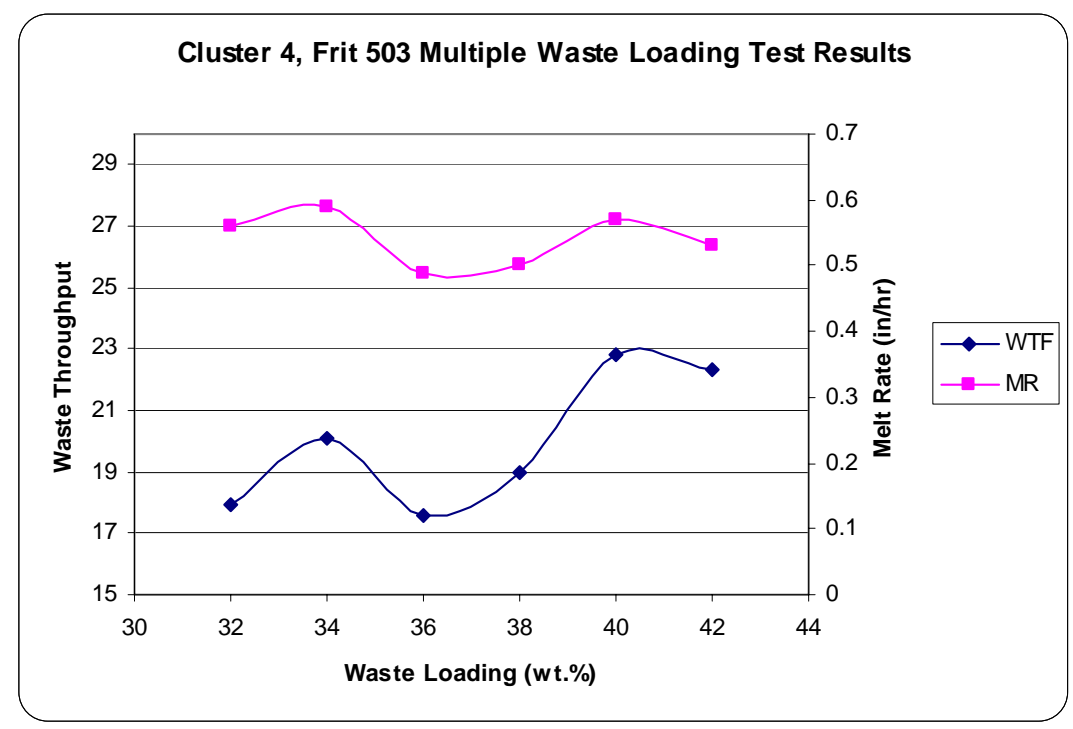


From past melt rate testing, Cluster 2 is similar to SB4 and the melt rate for SB4 was improved with high boron frits [9]. Cluster 4 is similar to SB3 in which melt rate was improved with high alkali (sodium) frits [11]. However, past trends with these components were not consistent with the results of the initial SMR tests, as Frit SMR-5 used for Cluster 2 is a high alkali frit, and Frit 503 used for Cluster 4 is a high boron frit. A possible explanation for the observed deviation from expected trends could be attributed to feed reduction/oxidation (REDOX) state.

\subsection{REDOX}

Given that the melt rate results did not follow previously observed trends, it was postulated that the oxidized condition of the feed might be impacting melt rate, which later testing proved to be true. The DWPF uses a REDOX strategy and controls the melt REDOX between $0.09 \leq$ $\mathrm{Fe}^{2+} / \Sigma \mathrm{Fe} \leq 0.33$. Controlling the DWPF melter at an equilibrium of $\mathrm{Fe}^{+2} / \Sigma \mathrm{Fe} \leq 0.33$ prevents metallic and sulfide rich species from forming nodules that can accumulate on the floor of the melter. Control of foaming, due to deoxygenation of manganic species, is achieved by converting oxidized $\mathrm{MnO}_{2}$ or $\mathrm{Mn}_{2} \mathrm{O}_{3}$ species to $\mathrm{MnO}$ during melter preprocessing. At the lower redox limit of $\mathrm{Fe}^{+2} / \Sigma \mathrm{Fe} \sim 0.09$ about $99 \%$ of the $\mathrm{Mn}^{+4} / \mathrm{Mn}^{+3}$ is converted to $\mathrm{Mn}^{+2}$. Therefore, the lower REDOX limit eliminates melter foaming from deoxygenation.

Organic, nitrate, and manganese concentrations in the DWPF melter feed are the major parameters influencing melt REDOX. Organics such as formats, coal, and oxalate act as reductants, while nitrates, nitrites, and manganic $\left(\mathrm{Mn}^{+4}\right.$ and $\left.\mathrm{Mn}^{+3}\right)$ species act as oxidants.

\subsubsection{SRAT Adjustment}

SRAT product for Clusters 2 and 4 were vitrified with Frit 418 in a closed crucible according to procedure ITS-0052. Analyses were conducted on these products and were determined to be nearly completely oxidized, as shown in Table 5-5.

Table 5-5: Initial REDOX values for Clusters 2 and 4 SRAT products.

\begin{tabular}{||c|c|c||}
\hline Sample & Cluster & REDOX \\
\hline MRF-08-11 & 4 & 0.019 \\
\hline MRF-08-12 & 4 & 0.021 \\
\hline MRF-08-13 & 4 & 0.116 \\
\hline MRF-08-17 & 2 & All Fe $^{3+}$ \\
\hline MRF-08-18 & 2 & 0.045 \\
\hline MRF-08-19 & 2 & All Fe $^{3+}$ \\
\hline
\end{tabular}

Calculations were performed to determine the amount of formic acid needed to adjust the redox to a more desirable ratio. It was determined that an additional $19.5 \mathrm{~g}$ formic acid were needed per $1000 \mathrm{~g}$ of Cluster 2 SRAT product, and $21.9 \mathrm{~g}$ formic acid per $1000 \mathrm{~g}$ Cluster 4 SRAT product to meet the 0.2 target. The REDOX adjustment was made after the initial melt rate testing had occurred; therefore, additional MRF runs were performed in order to re-assess the impact of aluminum dissolution on melt rate. Prior to utilizing the formic acid adjusted SRAT product, closed crucible testing (adjusted SRAT product with Frit 418 at $36 \% \mathrm{WL}$ ) was performed to verify that the revised acid strategy would yield a REDOX of $\sim 0.2$ and mitigate any confounding effects of REDOX on subsequent MRF testing. Analysis of the adjusted SRAT product (after the closed crucible test) indicate that a more suitable REDOX value of 0.2 was achieved, Table 5-6. 
SRNS-STI-2008-00081

Revision 0

Table 5-6: Final REDOX values for Clusters 2 and 4 SRAT products

after adjustment with formic acid.

\begin{tabular}{||c|c|c||}
\hline Sample & Cluster & REDOX \\
\hline SMR2-1 & 2 & 0.176 \\
\hline SMR2-2 & 2 & 0.191 \\
\hline SMR2-3 & 2 & 0.198 \\
\hline SMR4-1 & 4 & 0.262 \\
\hline SMR4-2 & 4 & 0.287 \\
\hline SMR4-3 & 4 & 0.267 \\
\hline
\end{tabular}

\subsection{Additional MRF Runs with the "REDOX” Adjusted SRAT Products}

Based on the potential impacts of REDOX on melt rate (potentially leading to inconsistencies with historical trends), additional MRF runs were planned. A significant shift in strategy was used in this phase of testing. Although the primary focus on this second set of MRF tests was to gain insight into the impacts of Al-dissolution on melt rate, the selection of frits to be used was altered, as will be described in Section 5.4.1. This subsequent testing will be referred to as Phase 3.

\subsubsection{Phase 3 Frit Composition Selection}

To support Phase 1, the frit selection was primarily driven from the ability of the frit to provide relatively large operating windows for both Cluster 2 and Cluster 4 as well as being MAR acceptable. As discussed in previous sections, although conceptually effective, the MRF results suggested melt rate trends that were inconsistent with historical trends observed in both SRNL testing as well as in DWPF operations. The frit selection for Phase 1 was also rather limited from a compositional perspective and did not provide the opportunity to assess specific compositional impacts. For Phase 3, the selection of frit compositions was based strictly on providing the opportunity to gain insight into the specific compositional effects of interest without regard to projected operating windows. That is, design a set of frits that would challenge previous melt rate trends by spanning a relatively large composition region and ignore the requirement of being MAR acceptable or providing reasonable operating windows.

Frit compositions for Phase 3 are listed in Table 5-7. A primary driver for this selection process was to minimize the number of frit components changing and to establish a basis from which direct comparisons could be made. For example, all of the Phase 3 frits have a fixed $\mathrm{Li}_{2} \mathrm{O}$ content. The first three frits shown in Table 3-7 also have a fixed $\mathrm{B}_{2} \mathrm{O}_{3}$ content with the $\mathrm{Na}_{2} \mathrm{O}$ contents ranging from 12\% (in Frit 320) to 3\% (in Frit 422) - $\mathrm{SiO}_{2}$ making up the difference. This series of frits should provide the opportunity to assess the impact of higher $\mathrm{Na}_{2} \mathrm{O}$ contents on melt rate for both with and without Al-dissolution. The later two frits (Frit 510 and 1888) fix both the $\mathrm{Na}_{2} \mathrm{O}$ and $\mathrm{Li}_{2} \mathrm{O}$ concentrations but vary in $\mathrm{B}_{2} \mathrm{O}_{3}$ content. These frits, along with Frit 422 will provide insight into the impact of higher $\mathrm{B}_{2} \mathrm{O}_{3}$ contents on melt rate for both flowsheets. 
Table 5-7: Frit Composition for Additional MRF Runs

\begin{tabular}{|c|c|c|c|c||}
\hline \hline Frit & $\mathrm{B}_{2} \mathrm{O}_{3}$ & $\mathrm{Na}_{2} \mathrm{O}$ & $\mathrm{Li}_{2} \mathrm{O}$ & $\mathrm{SiO}_{2}$ \\
\hline 320 & 8 & 12 & 8 & 72 \\
\hline 418 & 8 & 8 & 8 & 76 \\
\hline 422 & 8 & 3 & 8 & 81 \\
\hline 510 & 14 & 8 & 8 & 70 \\
\hline 1888 & 18 & 8 & 8 & 72 \\
\hline
\end{tabular}

\subsubsection{MRF Results}

Melt rate tests were performed as detailed in the melt rate run plan [12]. SRAT product, adjusted for REDOX, from Cluster 2 and Cluster 4 were used at a waste loading target of $36 \%$. The melt rate results are presented in Table 5-8 and Table 5-9.

Table 5-8: Cluster 2 Melt Rate Data for Phase 3 Frits

\begin{tabular}{||c|c|c|c|c||}
\hline \hline Cluster & Frit & WL & LMR (in/hr) & WTF \\
\hline 2 & 320 & 36 & 0.61 & 22.0 \\
\hline 2 & 418 & 36 & 0.48 & 17.3 \\
\hline 2 & 510 & 36 & 0.67 & 24.1 \\
\hline 2 & 1888 & 36 & 0.62 & 22.3 \\
\hline
\end{tabular}

Table 5-9: Cluster 4 Melt Rate Data for Phase 3 Frits

\begin{tabular}{||c|c|c|c|c||}
\hline \hline Cluster & Frit & WL & LMR (in/hr) & WTF \\
\hline 4 & 320 & 36 & 0.71 & 25.6 \\
\hline 4 & 418 & 36 & 0.63 & 22.7 \\
\hline 4 & 510 & 36 & 0.81 & 29.2 \\
\hline 4 & 1888 & 36 & 0.79 & 28.4 \\
\hline
\end{tabular}

The data presented in Figure 5-3 support trends seen in the past, with the exception of Cluster 4 (with Al-dissolution). Previous results indicated that the melt rate driver for low $\mathrm{Al}_{2} \mathrm{O}_{3} \mathrm{SB} 3$ (i.e. Cluster 4) was mainly sodium concentration, with boron having little effect [8]. However, examination of the data in 
Figure 5-4 would lead one to draw the conclusion that boron provides a greater contribution to melt rate than was previously expected. Frits 418, 1888, and 520 all had the same sodium concentration at $8 \mathrm{wt} . \%$. As lithium is held constant throughout all frits tested in this batch, boron concentration appears to be either the limiting or enabling constraint. When the sum of boron and sodium concentrations are considered as the driving force for melt rate in these scenarios, the expected trend can be seen, as in Figure 5-3.

Caution must be taken, however, with the interpretation of these data, as these frits were selected without consideration to MAR acceptability and is devoid of any impacts that may be caused due to rheology constraints.

When considering MAR acceptability, only Frits 418, 320, and 418 pass MAR criteria for Cluster 2, while 422 and 418 pass for Cluster 4 (Figure 5-5). MAR results for these frits can be found in Appendix, Table A6 and are graphically represented in Figure 3-7. The results obtained from Figure 5-5 supports the trends seen for previous sludge batches. SB3 was analogous to Cluster 4. SB3 was processed using Frit 418, just as the highest MR for a MAR acceptable frit was with Frit 418. SB4 was similar to Cluster 2. SB4 is being processed with Frit 510. For Cluster 2, Frit 510 had the highest MR of the frits that were tested. Based on the MAR acceptable frits, there does appear to be a slight advantage in melt rate with the "without Al-dissolution" flowsheet using Frit 510 as compared to the Frit 418 based "with Al-dissolution flowsheet". However, the reader is cautioned on two fronts: (1) the difference in melt rate data between these two systems may be within the uncertainty of the MRF (i.e., although a higher melt rate was measured for the Frit 510 based system, the two systems may not be of practical difference) and (2) the possible impacts of feed rheology are not accounted for in either system which could acerbate a difference if accounted for.

Figure 5-3: Graphical Representation of Cluster 4 Melt Rate Data for All Phase 3 Frits (MAR independent)

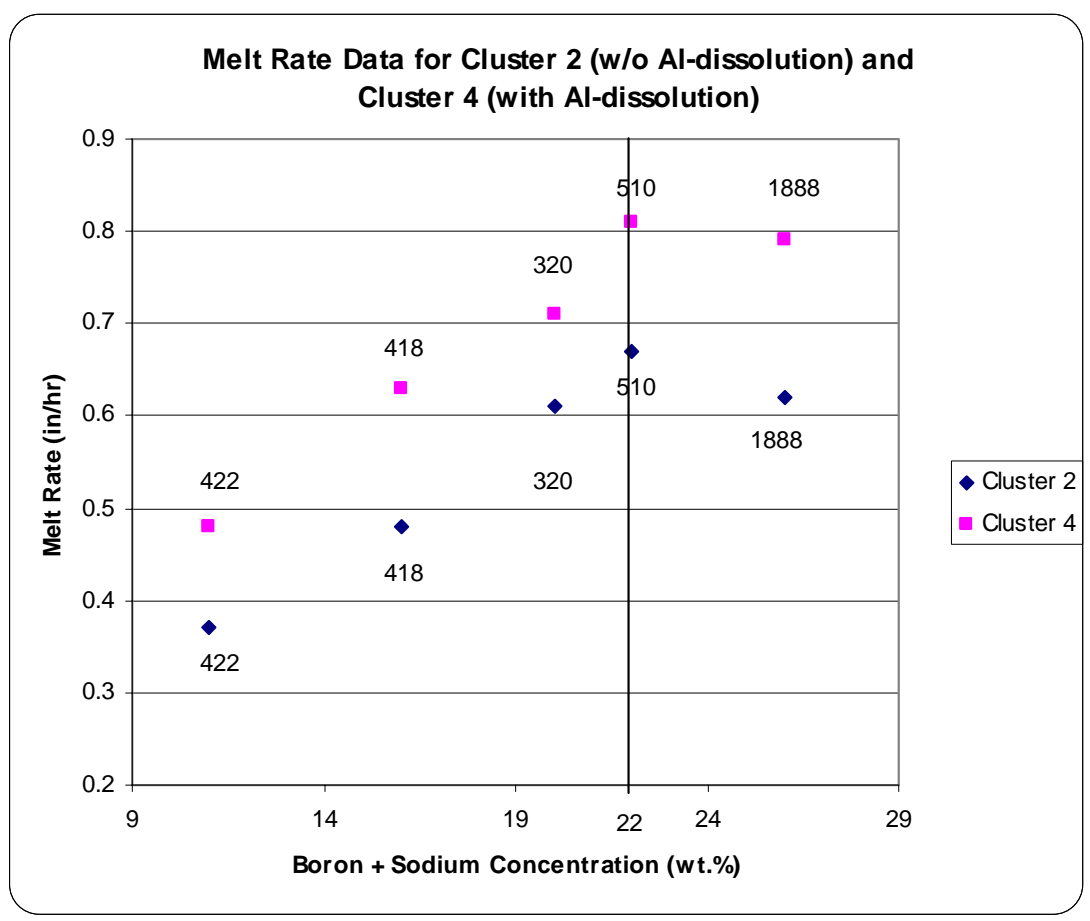


SRNS-STI-2008-00081

Revision 0

Figure 5-4: Melt Rate for Clusters 2 and 4 with Respect to Sodium Concentration

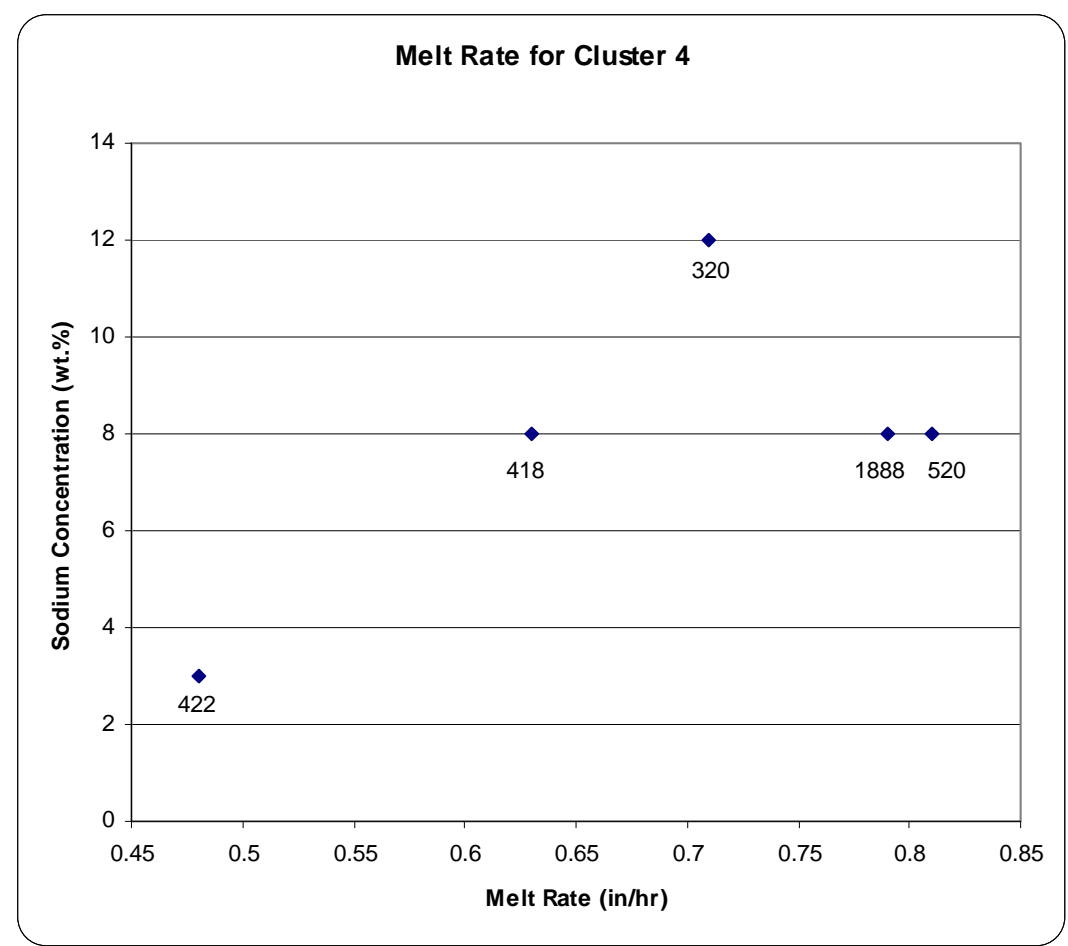

Figure 5-5: MAR acceptability enforced for Phase 3 frits 


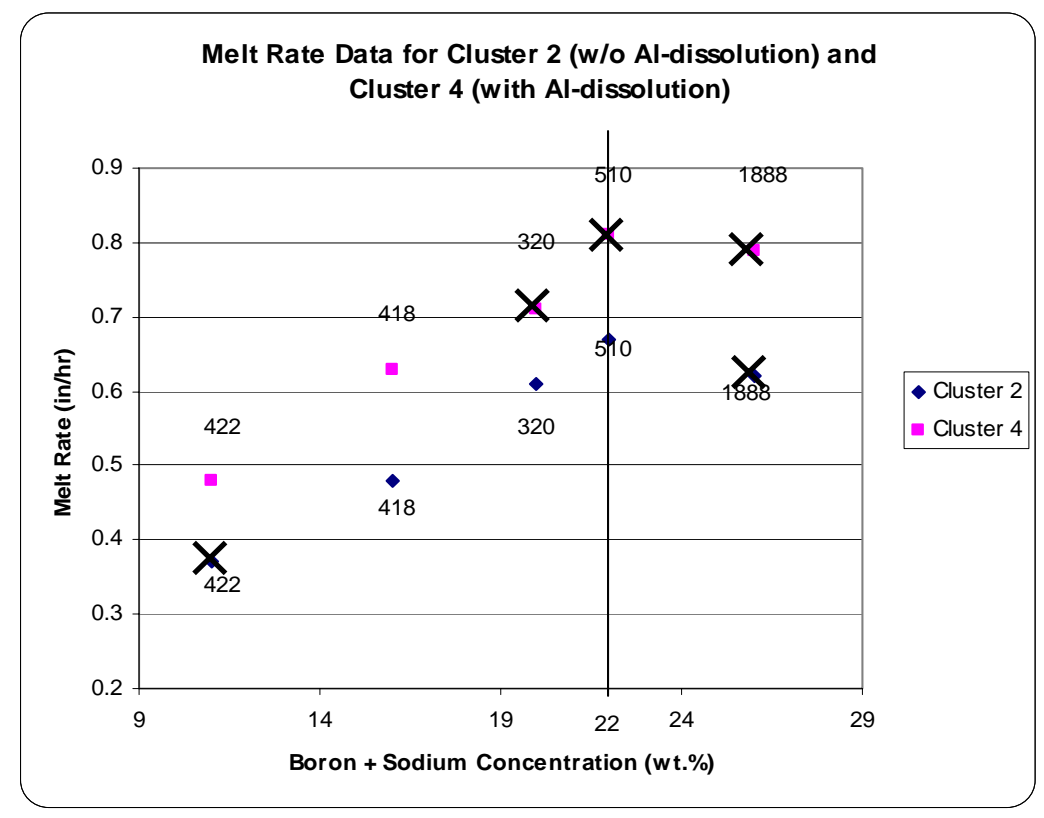

\subsection{Conclusion}

The objective of this study was to provide assessments of some of the downstream impacts of decisions regarding the implementation of Al-dissolution to support sludge mass reduction and processing, with respect to melt rate. Based on future sludge batch compositional projections, assessments have been made with respect to the ability to maintain comparable projected operating windows for sludges with and without Al-dissolution. Twelve sludge batches were identified based on implementation of high temperature Al-dissolution, while fourteen sludge batches represent the without Al-dissolution flowsheet. The assessments utilized two primary metrics to evaluate differences between the two flowsheet options: (1) the projected operating window size, defined as the waste loading interval over which glasses are classified as acceptable using current process control models, and (2) the number of frits that provide relatively large operating windows, which provides insight into the potential to adjust melt rate for a specific sludge batch.

In general, paper study assessments indicated that most of the future sludge batches, both with and without Al-dissolution, had multiple frits that were available that yielded relatively large operating windows. Using the 17-point waste loading window width as a guide for "reasonable operating window size", there generally appeared to be more flexibility in frit selection for the without Al-dissolution flowsheets. This larger frit compositional platform could allow frit development efforts to make more significant adjustments to melt rate, which ultimately could lead to a shorter mission life.

Based on the general observations of the paper study assessments there is essentially no clear distinction between the two flowsheets based on the projected operating windows to drive an Aldissolution decision. Comparable operating windows for both flowsheets can be achieved through the frit development and selection process. However, these conclusions did not address 
one of the key issues: melt rate. Does aluminum dissolution have any effect, be it positive or negative, on melt rate?

To address this question, candidate frit compositions were selected to assess melt rate as a function of waste loading for the glass systems representing average "with" and "without" Al dissolution flowsheets (based on a cluster analysis). These frits were chosen to provide the best opportunity to show the optimal operating windows for all future sludge batches and to ensure experimental assessments of melt rate for both with and without Al-dissolution were represented under the best possible conditions.

This frit selection process was driven by reviewing compositional trends that have been seen historically to influence melt rate as well as identifying systems with relatively large operating windows. More specifically, increasing the $\mathrm{Na}_{2} \mathrm{O}$ content (typically used for PUREX or high $\mathrm{Fe}_{2} \mathrm{O}_{3}$ sludges - e.g., SB3) and increasing the boron and/or sodium content (typically used for $\mathrm{HM}$ or high $\mathrm{Al}_{2} \mathrm{O}_{3}$ sludges - e.g., SB4) are strategies that were pursued. With respect to the identification of sludge batches, average compositions representing with and without Aldissolution, Clusters 2 and 4, were developed using a statistical grouping routine. Ultimately, five frits were identified for each cluster that utilized the historical trends in composition that have influenced melt rate in DWPF operations. For each cluster, melt rate assessments were performed as a function of waste loading for the five frits selected.

From the data obtained in the initial melt rate experiments, the maximum WTF for the without Al-dissolution Cluster 2 / SMR-5 feed was 25.6. The maximum WTF for the Al-dissolution Cluster 4 / Frit 503 feed was 22.8. Therefore, for this set of MRF tests, without Al-dissolution Cluster 2 feed had a WTF that was about $12 \%$ higher than Cluster 4 . This data was deemed to be suspect due to the REDOX conditions of the feed. After feed adjustment, additional tests were performed in which Frit 510 proved to have the best melt rate of the selected frits for both clusters. The linear melt rate for Cluster 4 (with Al-dissolution) was slightly better than for Cluster 2 (w/o Al-dissolution) at 0.81 to $0.67 \mathrm{in} / \mathrm{hr}$, respectively. This is the case until MAR constraints are applied. When considering MAR acceptability, only Frits 418,320 , and 510 pass MAR criteria for Cluster 2, while 422 and 418 pass for Cluster 4. Evaluating the MRF data for only the MAR acceptable frits, there appears to be a slight advantage of the Frit 510 based system without Aldissolution relative to the Frit 418 based system with Al-dissolution. The melt rate data are in general agreement with historical trends observed at SRNL and during processing of SB3 and SB4 in DWPF. However, the reader is cautioned on two fronts: (1) the difference in melt rate data between these two systems may be within the uncertainty of the MRF (i.e., although a higher melt rate was measured for the Frit 510 based system, the two systems may not be of practical difference) and (2) the possible impacts of feed rheology are not accounted for in either system which could acerbate a difference.

\subsection{Recommendation / Path Forward}

It should be noted that the MRF utilizes dried Sludge Receipt and Adjustment Tank (SRAT) product (targeting the nominal cluster compositions) coupled with a frit at a targeted waste loading. The MRF does not have the ability to assess liquid feeds and, thus, rheology impacts. Instead, the MRF is a "static" test bed in which a mass of dried melter feed (SRAT product plus frit) is placed in an "isothermal" furnace for a period of time to assess melt rate. These conditions, although historically effective in terms of identifying candidate frits for specific sludge batches and mapping out melt rate versus waste loading trends, do not allow for assessments of the potential impact of feed rheology on melt rate. That is, if the rheological properties of the slurried melter feed resulted in the mounding of the feed in the melter (i.e., the 
melter feed was thick and did not flow across the cold cap), melt rate and/or melter operations (i.e., surges) could be negatively impacted. Given the results of recent rheological measurements on SB4 and SB5, the possibility of this phenomenon exists. Slurry-fed Melt Rate Furnace testing using Clusters 2 and 4 could be performed in order to make a more informed decision on the impact of aluminum dissolution on DWPF throughput. This decision would need to be based on the ability of the simulant development program to produce a simulant mimicking the rheology of the radioactive sludge. If not, the SMRF testing would not capture this possible impact.

Although the Phase 3 testing did provide some degree of clarity regarding the compositional trends and their impact on melt rate, the tests were performed at only one waste loading $(36 \%)$. These data provide no insight into the waste throughput curves for the Frit 418 -Cluster 4 system or the Frit 510 - Cluster 2 system. That information is needed to provide additional insight into the mission life question. Without such data, one can only speculate on the waste loading that provide maximum throughput for each system.

Given the current schedule has DWPF processing SB5 through their facility in mid-November 2008 , insight into the over arching questions of melt rate, waste throughput, and mission life be best served or obtained directly from the facility. It is recommended that processing of SB5 through the facility be monitored closely and that data be used as input into the decision making process on whether to implement Al-dissolution for future sludge batches.

\subsection{References}

1. J.M.B. Pareizs, C.J.; Click, D.R.; Hansen, E.K.; Lambert, D.P.; Stone, M.E., Washing and Demonstration of the DWPF Flowsheet in the SRNL Shielded Cells using Post Aluminum Dissolution Tank 51 Sludge Slurry, WSRC-STI-2008-00086, Savannah River National Laboratory, Aiken, SC (2008)

2. C.C. Herman, Evaluation of LTAD Downstream Impacts - Status of SRNL 3L Tank 51 Sample Testing, SRNL-PSE-2007-00283, Washington Savannah River Company, Aiken, SC (2007)

3. J.R. Harbour, T.B. Edwards, E.K. Hansen, and V.J. Williams, Impact of Increased Aluminate Concentrations on Properties of Saltstone Mixes, WSRC-STI-2007-00506, Washington Savannah River Company, Aiken, SC (2007)

4. K.M. Fox and D.K. Peeler, Demonstration of Very High Aluminum Retention in Simulated HLW Glass, SRNL-PSE-2007-00231, Savannah River National Laboratory, Aiken, SC (2007)

5. J.D. Newell, Edwards, T.E., Peeler, D.K., Initial MAR Assessments to Access the Impact of Al-dissolution on DWPF Operating Windows, WSRC-STI-2007-00688, Washington Savannah River Company, Aiken, SC (2007)

6. D.K. Peeler, M.E. Smith, M.E. Stone, T.B. Edwards, and J.D. Newell, Frit Development for High $\mathrm{Al}_{2} \mathrm{O}_{3}$ Based Sludge: Task Technical and Quality Assurance Plan, Washington Savannah River Company, Aiken, SC (2007)

7. M.E. Smith, T.M. Jones, and D.H. Miller, Sludge Batch 4 Baseline Melt Rate Furnace and SlurryFed Melt Rate Furnace Tests with Frits 418 and 510, WSRC-STI-2007-00450, Washington Savannah River Company, Aiken, SC (2007)

8. $\quad$ M.E. Smith, Miller, D.H., Jones, T.M., Slurry-fed Melt Rate Furnace Test for the SB3/Frit 320 Feed System, WSRC-TR-2004-00459, Washington Savannah River Company, Aiken, SC (2004) 
9. $\quad$ M.E. Smith, Jones, T.M., Miller, D.H., Sludge Batch 4 Baseline Melt Rate Furnace and SlurryFed Melt Rate Furnace Tests with Frits 418 and 510, WSRC-STI-2007-00450, Washington Savannah River Company, Aiken, SC (2007)

10. D.H. Miller, Melt Rate Furnace Plane - Waste Loading for Aluminum Dissolution Frit, SRNLPSE-2008-00071, Washington Savannah River Company, Aiken, SC (2008)

11. M.E. Smith, Jones, T.M., Miller, D.H., Slurry-Fed Melt Rate Furnace Tests for the SB3/Frit 320 Feed System, WSRC-TR-2004-00459, Washington Savannah River Company, Aiken, SC (2004)

12. D.H. Miller, Melt Rate Furnace Tests for Sludge Mass Reduction Frit Selection, SRNL-PSE2008-00151, Washington Savannah River Company, Aiken, SC (2008) 
SRNS-STI-2008-00081

Revision 0

Appendix A 
Table A1. Projected Compositions With High Temperature Al-Dissolution: SB6 - SB17

(source: SBP_R-2_6_19_07_WAD)

\begin{tabular}{|c|c|c|c|c|c|c|c|c|c|c|c|c|}
\hline Oxide & SB6 & "SB7 & SB8 & SB9 & SB10 & SB11 & SB12 & PB13 & SB14 & SB15 & SB16 & SB17 \\
\hline $\mathrm{Al}_{2} \mathrm{O}_{3}$ & 22.827 & 18.228 & 13.449 & 12.577 & 11.945 & 13.564 & 17.461 & 16.577 & 15.648 & 13.044 & 13.663 & 13.810 \\
\hline $\mathrm{BaO}$ & 0.257 & 0.240 & 0.250 & 0.244 & 0.246 & 0.227 & 0.232 & 0.261 & 0.273 & 0.277 & 0.262 & 0.251 \\
\hline $\mathrm{CaO}$ & 1.909 & 2.896 & 2.959 & 3.391 & 3.659 & 3.510 & 3.652 & 3.405 & 3.243 & 2.905 & 2.950 & 2.935 \\
\hline $\mathrm{Ce}_{2} \mathrm{O}_{3}$ & 0.197 & 0.816 & 0.580 & 0.809 & 0.957 & 0.748 & 0.531 & 0.337 & 0.269 & 0.273 & 0.507 & 0.608 \\
\hline $\mathrm{Cr}_{2} \mathrm{O}_{3}$ & 0.312 & 0.255 & 0.311 & 0.297 & 0.291 & 0.365 & 0.374 & 0.401 & 0.407 & 0.382 & 0.330 & 0.301 \\
\hline $\mathrm{CuO}$ & 0.097 & 0.077 & 0.095 & 0.085 & 0.082 & 0.080 & 0.123 & 0.132 & 0.135 & 0.130 & 0.112 & 0.101 \\
\hline $\mathrm{Fe}_{2} \mathrm{O}_{3}$ & 25.744 & 37.353 & 33.829 & 38.049 & 40.684 & 41.223 & 36.186 & 31.258 & 29.653 & 29.492 & 33.970 & 35.534 \\
\hline $\mathrm{K}_{2} \mathrm{O}$ & 0.166 & 0.157 & 0.197 & 0.193 & 0.192 & 0.198 & 0.284 & 0.289 & 0.286 & 0.260 & 0.225 & 0.205 \\
\hline $\mathrm{La}_{2} \mathrm{O}_{3}$ & 0.074 & 0.261 & 0.209 & 0.273 & 0.314 & 0.257 & 0.217 & 0.164 & 0.145 & 0.141 & 0.198 & 0.221 \\
\hline $\mathrm{MgO}$ & 0.618 & 0.560 & 0.459 & 0.522 & 0.569 & 0.578 & 0.453 & 0.406 & 0.381 & 0.345 & 0.389 & 0.404 \\
\hline $\mathrm{MnO}$ & 8.788 & 6.887 & 10.664 & 8.243 & 6.693 & 3.812 & 4.259 & 3.153 & 2.681 & 2.934 & 2.391 & 2.094 \\
\hline $\mathrm{Na}_{2} \mathrm{O}$ & 19.910 & 20.314 & 20.620 & 21.289 & 21.410 & 21.712 & 21.879 & 21.452 & 21.177 & 21.216 & 21.017 & 20.624 \\
\hline $\mathrm{NiO}$ & 4.510 & 1.974 & 2.118 & 1.089 & 0.650 & 0.447 & 0.337 & 1.218 & 1.614 & 1.828 & 1.494 & 1.309 \\
\hline $\mathrm{PbO}$ & 0.087 & 0.338 & 0.247 & 0.332 & 0.389 & 0.295 & 0.251 & 0.170 & 0.143 & 0.148 & 0.236 & 0.274 \\
\hline $\mathrm{SO}_{4}$ & 1.878 & 0.607 & 0.510 & 0.288 & 0.158 & 0.108 & 0.090 & 0.151 & 0.176 & 0.231 & 0.198 & 0.183 \\
\hline $\mathrm{SiO}_{2}$ & 2.315 & 1.793 & 4.008 & 4.181 & 4.108 & 7.255 & 6.774 & 7.017 & 6.758 & 5.219 & 3.804 & 3.126 \\
\hline $\mathrm{ThO}_{2}$ & 1.208 & 0.642 & 3.117 & 3.077 & 3.086 & 1.253 & 0.538 & 0.201 & 0.089 & 0.031 & 0.012 & 0.005 \\
\hline $\mathrm{TiO}_{2}$ & 1.116 & 2.717 & 2.783 & 2.810 & 2.817 & 2.876 & 2.885 & 2.829 & 2.798 & 2.696 & 2.499 & 3.891 \\
\hline $\mathrm{U}_{3} \mathrm{O}_{8}$ & 7.460 & 3.250 & 2.910 & 1.537 & 1.013 & 0.630 & 2.571 & 9.726 & 13.293 & 17.656 & 14.993 & 13.400 \\
\hline $\mathrm{ZnO}$ & 0.143 & 0.081 & 0.117 & 0.084 & 0.068 & 0.243 & 0.238 & 0.215 & 0.210 & 0.206 & 0.162 & 0.140 \\
\hline $\mathrm{ZrO}_{2}$ & 0.384 & 0.557 & 0.568 & 0.627 & 0.668 & 0.618 & 0.666 & 0.639 & 0.622 & 0.585 & 0.589 & 0.583 \\
\hline
\end{tabular}


Table A2. Projected Compositions Without High Temperature Al-Dissolution: SB6 - SB19

(source: SBP R-1 7 12 06 NAD)

\begin{tabular}{|c|c|c|c|c|c|c|c|c|c|c|c|c|c|c|}
\hline Oxide & "SB6 & SB7 & SB8 & SB9 & SB10 & SB11 & SB12 & SB13 & SB14 & "SB15 & SB16 & SB17 & SB18 & SB19 \\
\hline $\mathrm{Al}_{2} \mathrm{O}_{3}$ & 25.734 & 25.242 & 25.619 & 25.779 & 25.825 & 26.600 & 22.827 & 20.047 & 19.139 & 22.583 & 26.589 & 30.316 & 32.653 & 34.308 \\
\hline $\mathrm{BaO}$ & 0.230 & 0.206 & 0.196 & 0.192 & 0.191 & 0.160 & 0.190 & 0.219 & 0.273 & 0.245 & 0.200 & 0.183 & 0.180 & 0.183 \\
\hline $\mathrm{CaO}$ & 1.741 & 2.432 & 2.732 & 2.829 & 2.860 & 2.448 & 2.314 & 2.380 & 2.340 & 2.736 & 2.891 & 2.862 & 2.809 & 2.837 \\
\hline $\mathrm{Ce}_{2} \mathrm{O}_{3}$ & 0.120 & 0.529 & 0.723 & 0.787 & 0.807 & 0.677 & 0.540 & 0.325 & 0.208 & 0.245 & 0.640 & 0.407 & 0.258 & 0.196 \\
\hline $\mathrm{Cr}_{2} \mathrm{O}_{3}$ & 0.285 & 0.244 & 0.224 & 0.216 & 0.214 & 0.238 & 0.241 & 0.296 & 0.358 & 0.344 & 0.250 & 0.271 & 0.303 & 0.323 \\
\hline $\mathrm{CuO}$ & 0.071 & 0.066 & 0.063 & 0.062 & 0.062 & 0.051 & 0.071 & 0.093 & 0.100 & 0.135 & 0.089 & 0.117 & 0.095 & 0.085 \\
\hline $\mathrm{Fe}_{2} \mathrm{O}_{3}$ & 21.811 & 28.667 & 31.980 & 33.063 & 33.416 & 34.253 & 29.807 & 25.694 & 24.350 & 28.550 & 33.562 & 29.271 & 21.828 & 18.705 \\
\hline $\mathrm{K}_{2} \mathrm{O}$ & 0.238 & 0.192 & 0.167 & 0.159 & 0.156 & 0.130 & 0.151 & 0.189 & 0.187 & 0.271 & 0.196 & 0.258 & 0.226 & 0.213 \\
\hline $\mathrm{La}_{2} \mathrm{O}_{3}$ & 0.085 & 0.192 & 0.242 & 0.258 & 0.263 & 0.221 & 0.188 & 0.138 & 0.106 & 0.135 & 0.227 & 0.176 & 0.126 & 0.105 \\
\hline $\mathrm{MgO}$ & 0.863 & 0.584 & 0.496 & 0.468 & 0.460 & 0.430 & 0.355 & 0.322 & 0.347 & 0.273 & 0.383 & 0.280 & 0.337 & 0.375 \\
\hline $\mathrm{MnO}$ & 8.788 & 7.873 & 6.429 & 5.904 & 5.739 & 4.148 & 3.001 & 1.876 & 1.214 & 3.292 & 2.387 & 4.102 & 2.549 & 1.786 \\
\hline $\mathrm{Na}_{2} \mathrm{O}$ & 20.909 & 20.128 & 20.057 & 20.061 & 20.050 & 19.545 & 19.119 & 19.305 & 21.887 & 21.092 & 20.891 & 20.754 & 26.436 & 27.853 \\
\hline $\mathrm{NiO}$ & 3.942 & 1.900 & 0.970 & 0.664 & 0.569 & 0.360 & 0.810 & 1.244 & 2.697 & 1.665 & 0.560 & 0.172 & 0.260 & 0.319 \\
\hline $\mathrm{PbO}$ & 0.055 & 0.220 & 0.298 & 0.324 & 0.332 & 0.276 & 0.234 & 0.151 & 0.087 & 0.159 & 0.288 & 0.226 & 0.119 & 0.070 \\
\hline $\mathrm{SO}_{4}$ & 0.722 & 0.311 & 0.214 & 0.186 & 0.177 & 0.184 & 0.184 & 0.164 & 0.161 & 0.206 & 0.227 & 0.236 & 0.191 & 0.168 \\
\hline $\mathrm{SiO}_{2}$ & 3.569 & 3.075 & 2.710 & 2.584 & 2.544 & 3.729 & 2.748 & 4.112 & 5.192 & 4.064 & 2.980 & 3.514 & 6.631 & 8.271 \\
\hline $\mathrm{ThO}_{2}$ & 1.659 & 1.713 & 1.625 & 1.592 & 1.580 & 1.836 & 1.586 & 0.769 & 0.248 & 0.076 & 0.023 & 0.007 & 0.002 & 0.001 \\
\hline $\mathrm{TiO}_{2}$ & 2.517 & 3.043 & 3.198 & 3.245 & 3.259 & 3.353 & 3.263 & 3.256 & 3.209 & 3.314 & 3.194 & 2.145 & 2.729 & 3.096 \\
\hline $\mathrm{U}_{3} \mathrm{O}_{8}$ & 6.218 & 2.853 & 1.491 & 1.051 & 0.915 & 0.714 & 11.770 & 18.797 & 17.278 & 9.821 & 3.756 & 3.960 & 1.651 & 0.542 \\
\hline $\mathrm{ZnO}$ & 0.108 & 0.076 & 0.060 & 0.054 & 0.053 & 0.201 & 0.148 & 0.151 & 0.143 & 0.231 & 0.118 & 0.193 & 0.125 & 0.092 \\
\hline $\mathrm{ZrO}_{2}$ & 0.335 & 0.455 & 0.506 & 0.522 & 0.528 & 0.447 & 0.453 & 0.470 & 0.477 & 0.562 & 0.549 & 0.551 & 0.493 & 0.473 \\
\hline
\end{tabular}


Table A3: Acid Equation Inputs and Results

\begin{tabular}{|c|c|c|c|}
\hline Sludge Analyses for Acid Calculations & SMR-2 & SMR-4 & \\
\hline Fresh Sludge Mass without trim chemicals & $16,500.0$ & $16,700.0$ & g slurry \\
\hline Fresh Sludge Weight \% Total Solids & 22.85 & 22.55 & $\mathrm{wt} \%$ \\
\hline Fresh Sludge Weight $\%$ Calcined Solids & 17.00 & 17.40 & $\mathrm{wt} \%$ \\
\hline Fresh Sludge Weight \% Insoluble Solids & 16.20 & 15.95 & $\mathrm{wt} \%$ \\
\hline Fresh Sludge Density & 1.210 & 1.210 & $\mathrm{~kg} / \mathrm{L}$ slurry \\
\hline Fresh Sludge Nitrite & 16,700 & 14,000 & $\mathrm{mg} / \mathrm{kg}$ slurry \\
\hline Fresh Sludge Nitrate & 9,870 & 9,205 & $\mathrm{mg} / \mathrm{kg}$ slurry \\
\hline Fresh Sludge Oxalate & 879 & 2845 & $\mathrm{mg} / \mathrm{kg}$ slurry \\
\hline Fresh Sludge Formate & 0 & 0 & $\mathrm{mg} / \mathrm{kg}$ slurry \\
\hline Fresh Sludge Coal/Carbon source & 0.000 & 0.000 & wt $\%$ dry basis \\
\hline Fresh Sludge Manganese ( $\%$ of Calcined Solids) & 2.690 & 3.445 & wt $\%$ calcined basis \\
\hline Fresh Sludge Slurry TIC (treated as Carbonate) & 923 & 872 & $\mathrm{mg} / \mathrm{kg}$ slurry \\
\hline Fresh Sludge Hydroxide (Base Equivalents) $\mathrm{pH}=7$ & 0.661 & 0.836 & Equiv Moles Base/L slurry \\
\hline Fresh Sludge Mercury (\% of Total Solids in untrimmed sludge) & 0.0000 & 0.0000 & wt $\%$ dry basis \\
\hline Fresh Sludge Supernate manganese & 0 & 0 & $\mathrm{mg} / \mathrm{L}$ supernate \\
\hline Fresh Sludge Supernate density & 1.04 & 1.04 & $\mathrm{~kg} / \mathrm{L}$ supernate \\
\hline SRAT Processing Assumptions & SMR-2 & SMR-4 & \\
\hline Conversion of Nitrite to Nitrate in SRAT Cycle & 25.00 & 25.00 & gmol NO$_{3}^{-} / 100$ gmol NO$_{2}^{-}$ \\
\hline Destruction of Nitrite in SRAT and SME cycle & 100.00 & 100.00 & $\%$ of starting nitrite destroyed \\
\hline Destruction of Formic acid charged in SRAT & 10.00 & 10.00 & $\%$ formate converted to $\mathrm{CO}_{2}$ etc. \\
\hline Destruction of oxalate charged & 50.00 & 50.00 & $\%$ of total oxalate destroyed \\
\hline Percent Acid in Excess Stoichiometric Ratio & 130.00 & 130.00 & $\%$ \\
\hline SRAT Product Target Solids & 25.00 & 25.00 & $\%$ \\
\hline Nitric Acid Molarity & 10.534 & 10.534 & Molar \\
\hline Formic Acid Molarity & 23.600 & 23.600 & Molar \\
\hline DWPF Nitric Acid addition Rate & 2.0 & 2.0 & gallons per minute \\
\hline DWPF Formic Acid addition Rate & 2.0 & 2.0 & gallons per minute \\
\hline REDOX Target & 0.200 & 0.200 & $\mathrm{Fe}^{+2} / \Sigma \mathrm{Fe}$ \\
\hline REDOX Equation ( 7 for $\mathrm{Mn}^{+7}$, otherwise assumes $\mathrm{Mn}^{+4}$ ) & 7 & 7 & Enter 7 for new redox equation \\
\hline Trimmed Sludge Target Ag metal content & 0.00000 & 0.00000 & total $w t \%$ dry basis after trim \\
\hline Trimmed Sludge Target wt $\%$ Hg dry basis & 0.00000 & 0.00000 & total wt $\%$ dry basis after trim \\
\hline Trimmed Sludge Target Pd metal content & 0.00000 & 0.00000 & total $\mathrm{wt} \%$ dry basis after trim \\
\hline Trimmed Sludge Target Rh metal content & 0.00000 & 0.00000 & total $\mathrm{wt} \%$ dry basis after trim \\
\hline Trimmed Sludge Target Ru metal content & 0.00000 & 0.00000 & total $\mathrm{wt} \%$ dry basis after trim \\
\hline Trimmed Sludge Target $\mathrm{Wt} \%$ Coal/carbon source dry basis & 0.00 & 0.00 & total $\mathrm{wt} \%$ dry basis after trim \\
\hline Trimmed Sludge Target oxalate after trim (wt \% not $\mathrm{mg} / \mathrm{kg}$ ) & 0.385 & 1.262 & total $\mathrm{wt} \%$ dry basis after trim \\
\hline Water to dilute fresh sludge and/or rinse trim chemicals & 500.000 & 500.000 & $\mathrm{~g}$ \\
\hline Total Water added to flush the Nitric and Formic Acid Lines & 50.0 & 50.0 & $\mathrm{~g}$ \\
\hline Sample Mass of Trimmed sludge (SRAT Receipt sample, if any) & 0.0 & 0.0 & $\mathrm{~g}$ \\
\hline Mass of SRAT cycle samples & 0.000 & 0.000 & $\mathrm{~g}$ \\
\hline Wt $\%$ Active Agent In Antifoam Solution & 10 & 10 & $\%$ \\
\hline $\begin{array}{l}\text { Basis Antifoam Addition for SRAT (generally } 100 \mathrm{mg} \\
\text { antifoam/kg slurry) }\end{array}$ & 100.00 & 100.00 & $\mathrm{mg} / \mathrm{kg}$ slurry \\
\hline Number of basis antifoam additions added during SRAT cycle & 7.00 & 7.00 & \\
\hline
\end{tabular}


SRNS-STI-2008-00081

Revision 0

\begin{tabular}{|l|l|l|l|}
\hline Results of Acid Calculation & & & \\
\hline & SMR-2 & SMR-4 & \\
\hline Acid Addition Amount & 1.61 & 1.85 & g/mol per liter \\
\hline Ratio of Formic Acid to total Acid & 0.891 & 0.867 & mol formic/mol acid \\
\hline
\end{tabular}




\section{Table A4: ICP Data for Frits 422 and 1888}

SRNL Process Science Analytical Laboratory Customer: David Newell

Date: $8 / 7 / 08$

Samples: Frit 422, Frit 1888

Lab ID: 08-1563-1564

Units: elemental and oxide wt $\%$

Sample Preparation: $\mathrm{LiBO} 2$ and $\mathrm{Na} 2 \mathrm{O} 2$ Preps

Comments: Samples run in duplicate

\begin{tabular}{|c|c|c|c|c|c|c|}
\hline Sample ID & Lab ID & $\mathrm{B}$ & $\mathrm{Li}$ & $\mathrm{Na}$ & $\mathrm{Si}$ & \\
\hline Frit 422(A) & $08-1563$ & 2.49 & 3.67 & 2.06 & 38.3 & \\
\hline Frit 422 (B) & $08-1563$ & 2.49 & 3.70 & 2.02 & 38.0 & \\
\hline Frit 1888(A) & $08-1564$ & 5.52 & 3.71 & 5.62 & 31.0 & \\
\hline Frit 1888 (B) & $08-1564$ & 5.50 & 3.72 & 5.61 & 30.8 & \\
\hline & & & & & & \\
\hline & & $\mathrm{B} 2 \mathrm{O} 3$ & $\mathrm{Li} 2 \mathrm{O}$ & $\mathrm{Na} 2 \mathrm{O}$ & $\mathrm{SiO} 2$ & Total \\
\hline & $08-1563$ & 8.02 & 7.89 & 2.8 & 82.0 & 100.7 \\
\hline Frit 422(A) & $08-1563$ & 8.02 & 7.96 & 2.7 & 81.3 & 100.0 \\
\hline Frit 422(B) & $08-1564$ & 17.8 & 7.98 & 7.59 & 66.3 & 99.7 \\
\hline Frit 1888(A) & $08-1564$ & 17.7 & 8.00 & 7.57 & 65.9 & 99.2 \\
\hline Frit 1888 (B)
\end{tabular}




\section{Table A5: ICP Data for SMR-X Frits}

SRNL Process Science Analytical Laboratory

Customer: David Newell

Date: $4 / 9 / 08$

Samples: SMR 1-8

Lab ID: 08-0795-0802

Units: elemental and oxide wt $\%$

Sample Preparation: $\mathrm{LiBO} 2$ and $\mathrm{Na} 2 \mathrm{O} 2$ Preps

Comments: Samples run in duplicate

\begin{tabular}{|c|c|c|c|c|c|c|c|c|}
\hline Sample ID & Lab ID & $\mathrm{Al}$ & $\mathrm{B}$ & $\mathrm{Ca}$ & $\mathrm{Li}$ & $\mathrm{Na}$ & $\mathrm{Si}$ & \\
\hline SMR-1 (A) & 08-0795 & 0.160 & 2.62 & 0.015 & 3.93 & 8.04 & 33.5 & \\
\hline SMR-1 (B) & 08-0795 & 0.152 & 2.63 & 0.015 & 3.98 & 7.98 & 33.5 & \\
\hline SMR-2 (A) & 08-0796 & 0.337 & 3.49 & 0.034 & 3.94 & 6.58 & 32.9 & \\
\hline SMR-2 (B) & 08-0796 & 0.332 & 3.61 & 0.031 & 3.95 & 6.49 & 32.5 & \\
\hline SMR-3 (A) & 08-0797 & 0.182 & 4.62 & 0.020 & 3.97 & 5.06 & 32.3 & \\
\hline SMR-3 (B) & 08-0797 & 0.180 & 4.59 & 0.019 & 3.96 & 5.21 & 32.9 & \\
\hline SMR-4 (A) & 08-0798 & 0.479 & 4.95 & 0.039 & 3.88 & 3.72 & 33.2 & \\
\hline SMR-4 (B) & 08-0798 & 0.482 & 5.03 & 0.030 & 3.90 & 3.79 & 33.2 & \\
\hline SMR-5 (A) & 08-0799 & 0.158 & 3.03 & 0.013 & 3.79 & 6.21 & 35.0 & \\
\hline SMR-5 (B) & 08-0799 & 0.155 & 2.91 & 0.013 & 3.89 & 6.03 & 35.3 & \\
\hline SMR-6 (A) & 08-0800 & 1.20 & 3.20 & 0.094 & 3.79 & 5.07 & 34.6 & \\
\hline SMR-6 (B) & 08-0800 & 1.18 & 3.13 & 0.092 & 3.77 & 5.13 & 34.5 & \\
\hline SMR-7 (A) & 08-0801 & 0.320 & 3.59 & 0.023 & 3.86 & 4.46 & 34.0 & \\
\hline SMR-7 (B) & 08-0801 & 0.355 & 3.58 & 0.025 & 3.86 & 4.68 & 34.1 & \\
\hline SMR-8 (A) & 08-0802 & 0.295 & 3.69 & 0.025 & 3.75 & 4.57 & 35.2 & \\
\hline SMR-8 (B) & 08-0802 & 0.313 & 3.69 & 0.028 & 3.75 & 4.66 & 35.8 & \\
\hline & & $\mathrm{Al} 2 \mathrm{O} 3$ & $\mathrm{~B} 2 \mathrm{O} 3$ & $\mathrm{CaO}$ & $\mathrm{Li} 2 \mathrm{O}$ & $\mathrm{Na} 2 \mathrm{O}$ & $\mathrm{SiO} 2$ & Total \\
\hline SMR-1 (A) & 08-0795 & 0.302 & 8.44 & 0.021 & 8.45 & 10.9 & 71.7 & 99.5 \\
\hline SMR-1 (B) & 08-0795 & 0.287 & 8.47 & 0.021 & 8.56 & 10.8 & 71.7 & 99.5 \\
\hline SMR-2 (A) & 08-0796 & 0.637 & 11.2 & 0.048 & 8.47 & 8.88 & 70.4 & 99.0 \\
\hline SMR-2 (B) & 08-0796 & 0.627 & 11.6 & 0.043 & 8.49 & 8.76 & 69.6 & 98.5 \\
\hline SMR-3 (A) & 08-0797 & 0.344 & 14.9 & 0.028 & 8.54 & 6.83 & 69.1 & 99.4 \\
\hline SMR-3 (B) & 08-0797 & 0.340 & 14.8 & 0.027 & 8.51 & 7.03 & 70.4 & 101 \\
\hline SMR-4 (A) & 08-0798 & 0.905 & 15.9 & 0.055 & 8.34 & 5.02 & 71.0 & 100 \\
\hline SMR-4 (B) & 08-0798 & 0.911 & 16.2 & 0.042 & 8.39 & 5.12 & 71.0 & 101 \\
\hline SMR-5 (A) & 08-0799 & 0.299 & 9.76 & 0.018 & 8.15 & 8.38 & 74.9 & 101 \\
\hline SMR-5 (B) & 08-0799 & 0.293 & 9.37 & 0.018 & 8.36 & 8.14 & 75.5 & 101 \\
\hline SMR-6 (A) & 08-0800 & 2.27 & 10.3 & 0.132 & 8.15 & 6.84 & 74.0 & 99.5 \\
\hline SMR-6 (B) & 08-0800 & 2.23 & 10.1 & 0.129 & 8.11 & 6.93 & 73.8 & 99.1 \\
\hline SMR-7 (A) & 08-0801 & 0.605 & 11.6 & 0.032 & 8.30 & 6.02 & 72.8 & 98.7 \\
\hline SMR-7 (B) & 08-0801 & 0.671 & 11.5 & 0.035 & 8.30 & 6.32 & 73.0 & 99.2 \\
\hline SMR-8 (A) & 08-0802 & 0.558 & 11.9 & 0.035 & 8.06 & 6.17 & 75.3 & 101 \\
\hline SMR-8 (B) & 08-0802 & 0.592 & 11.9 & 0.039 & 8.06 & 6.29 & 76.6 & 103 \\
\hline
\end{tabular}


Table A6: MAR acceptability of Phase 3 frits

\begin{tabular}{|c|c|c|c|}
\hline $\begin{array}{c}\% \\
\text { WL } \\
\end{array}$ & Frit & Sludge Type & MAR Status \\
\hline 25 & B-8;Li-8;Na-3;Si-81 & Cluster 2 avg & highv Homg \\
\hline 26 & B-8;Li-8;Na-3;Si-81 & Cluster 2 avg & highv \\
\hline 27 & B-8;Li-8;Na-3;Si-81 & Cluster 2 avg & highv \\
\hline 28 & B-8;Li-8;Na-3;Si-81 & Cluster 2 avg & highv \\
\hline 29 & B-8;Li-8;Na-3;Si-81 & Cluster 2 avg & highv \\
\hline 30 & B-8;Li-8;Na-3;Si-81 & Cluster 2 avg & highv \\
\hline 31 & B-8;Li-8;Na-3;Si-81 & Cluster 2 avg & highv \\
\hline 32 & B-8;Li-8;Na-3;Si-81 & Cluster 2 avg & highv \\
\hline 33 & B-8;Li-8;Na-3;Si-81 & Cluster 2 avg & highv \\
\hline 34 & B-8;Li-8;Na-3;Si-81 & Cluster 2 avg & highv \\
\hline 35 & B-8;Li-8;Na-3;Si-81 & Cluster 2 avg & highv \\
\hline 36 & B-8;Li-8;Na-3;Si-81 & Cluster 2 avg & highv \\
\hline 37 & B-8;Li-8;Na-3;Si-81 & Cluster 2 avg & highv \\
\hline 38 & B-8;Li-8;Na-3;Si-81 & Cluster 2 avg & highv \\
\hline 39 & B-8;Li-8;Na-3;Si-81 & Cluster 2 avg & \\
\hline 40 & B-8;Li-8;Na-3;Si-81 & Cluster 2 avg & \\
\hline 41 & B-8;Li-8;Na-3;Si-81 & Cluster 2 avg & \\
\hline 42 & B-8;Li-8;Na-3;Si-81 & Cluster 2 avg & $\mathrm{TL}$ \\
\hline 43 & B-8;Li-8;Na-3;Si-81 & Cluster 2 avg & $\mathrm{TL}$ \\
\hline 44 & B-8;Li-8;Na-3;Si-81 & Cluster 2 avg & TL \\
\hline 45 & B-8;Li-8;Na-3;Si-81 & Cluster 2 avg & $\mathrm{TL}$ \\
\hline 46 & B-8;Li-8;Na-3;Si-81 & Cluster 2 avg & $\mathrm{TL}$ \\
\hline 47 & B-8;Li-8;Na-3;Si-81 & Cluster 2 avg & TL \\
\hline 48 & B-8;Li-8;Na-3;Si-81 & Cluster 2 avg & $\mathrm{TL}$ \\
\hline 49 & B-8;Li-8;Na-3;Si-81 & Cluster 2 avg & TL \\
\hline 50 & B-8;Li-8;Na-3;Si-81 & Cluster 2 avg & $\mathrm{TL}$ \\
\hline 25 & B-8;Li-8;Na- $8 ;$ Si-76 & Cluster 2 avg & Homg \\
\hline 26 & B-8;Li-8;Na-8;Si-76 & Cluster 2 avg & \\
\hline 27 & B-8;Li-8;Na-8;Si-76 & Cluster 2 avg & \\
\hline 28 & B-8;Li-8;Na-8;Si-76 & Cluster 2 avg & \\
\hline 29 & B-8;Li-8;Na-8;Si-76 & Cluster 2 avg & \\
\hline 30 & B-8;Li-8;Na-8;Si-76 & Cluster 2 avg & \\
\hline 31 & B-8;Li-8;Na-8;Si-76 & Cluster 2 avg & \\
\hline 32 & B-8;Li-8;Na-8;Si-76 & Cluster 2 avg & \\
\hline 33 & B-8;Li-8;Na-8;Si-76 & Cluster 2 avg & \\
\hline 34 & B-8;Li-8;Na-8;Si-76 & Cluster 2 avg & \\
\hline 35 & B-8;Li-8;Na-8;Si-76 & Cluster 2 avg & \\
\hline 36 & B-8;Li-8;Na-8;Si-76 & Cluster 2 avg & \\
\hline 37 & B-8;Li-8;Na-8;Si-76 & Cluster 2 avg & \\
\hline 38 & B-8;Li-8;Na-8;Si-76 & Cluster 2 avg & \\
\hline 39 & B-8;Li-8;Na-8;Si-76 & Cluster 2 avg & \\
\hline 40 & B-8;Li-8;Na-8;Si-76 & Cluster 2 avg & \\
\hline 41 & B-8;Li-8;Na-8;Si-76 & Cluster 2 avg & \\
\hline 42 & B-8;Li-8;Na-8;Si-76 & Cluster 2 avg & \\
\hline 43 & B-8;Li-8;Na-8;Si-76 & Cluster 2 avg & \\
\hline 44 & B-8;Li-8;Na-8;Si-76 & Cluster 2 avg & \\
\hline
\end{tabular}




\begin{tabular}{|c|c|c|c|}
\hline 45 & B-8;Li-8;Na-8;Si-76 & Cluster 2 avg & \\
\hline 46 & B-8;Li-8;Na-8;Si-76 & Cluster 2 avg & \\
\hline 47 & B-8;Li-8;Na- $8 ;$ Si-76 & Cluster 2 avg & Neph \\
\hline 48 & B-8;Li-8;Na-8;Si-76 & Cluster 2 avg & TL Neph \\
\hline 49 & B-8;Li-8;Na-8;Si-76 & Cluster 2 avg & TL Neph \\
\hline 50 & B-8;Li-8;Na-8;Si-76 & Cluster 2 avg & TL Neph \\
\hline 25 & B-8;Li-8;Na-12;Si-72 & Cluster 2 avg & Homg \\
\hline 26 & B-8;Li-8;Na-12;Si-72 & Cluster 2 avg & \\
\hline 27 & B-8;Li-8;Na-12;Si-72 & Cluster 2 avg & \\
\hline 28 & B-8;Li- $8 ; \mathrm{Na}-12 ; \mathrm{Si}-72$ & Cluster 2 avg & \\
\hline 29 & B-8;Li-8;Na-12;Si-72 & Cluster 2 avg & \\
\hline 30 & B-8;Li-8;Na-12;Si-72 & Cluster 2 avg & \\
\hline 31 & B-8;Li- $8 ; \mathrm{Na}-12 ; \mathrm{Si}-72$ & Cluster 2 avg & \\
\hline 32 & B-8;Li-8;Na-12;Si-72 & Cluster 2 avg & \\
\hline 33 & B-8;Li-8;Na-12;Si-72 & Cluster 2 avg & \\
\hline 34 & B-8;Li-8;Na-12;Si-72 & Cluster 2 avg & \\
\hline 35 & B-8;Li-8;Na-12;Si-72 & Cluster 2 avg & \\
\hline 36 & B-8;Li- $8 ; \mathrm{Na}-12 ; \mathrm{Si}-72$ & Cluster 2 avg & \\
\hline 37 & B-8;Li-8;Na-12;Si-72 & Cluster 2 avg & \\
\hline 38 & B-8;Li-8;Na-12;Si-72 & Cluster 2 avg & \\
\hline 39 & B-8;Li-8;Na-12;Si-72 & Cluster 2 avg & \\
\hline 40 & B-8;Li-8;Na-12;Si-72 & Cluster 2 avg & \\
\hline 41 & B- $8 ; \mathrm{Li}-8 ; \mathrm{Na}-12 ; \mathrm{Si}-72$ & Cluster 2 avg & lowv \\
\hline 42 & B-8;Li-8;Na-12;Si-72 & Cluster 2 avg & lowv \\
\hline 43 & B-8;Li-8;Na-12;Si-72 & Cluster 2 avg & lowv Neph \\
\hline 44 & B- $8 ; \mathrm{Li}-8 ; \mathrm{Na}-12 ; \mathrm{Si}-72$ & Cluster 2 avg & lowv Neph \\
\hline 45 & B-8;Li-8;Na-12;Si-72 & Cluster 2 avg & lowv Neph \\
\hline 46 & B-8;Li-8;Na-12;Si-72 & Cluster 2 avg & lowv Neph \\
\hline 47 & B-8;Li-8;Na-12;Si-72 & Cluster 2 avg & lowv Neph \\
\hline 48 & B-8;Li-8;Na-12;Si-72 & Cluster 2 avg & lowv Neph \\
\hline 49 & B- $8 ; \mathrm{Li}-8 ; \mathrm{Na}-12 ; \mathrm{Si}-72$ & Cluster 2 avg & lowv Neph \\
\hline 50 & B-8;Li-8;Na-12;Si-72 & Cluster 2 avg & lowv Neph \\
\hline 25 & B-14;Li-8;Na-8;Si-70 & Cluster 2 avg & Homg \\
\hline 26 & B-14;Li-8;Na-8;Si-70 & Cluster 2 avg & \\
\hline 27 & B-14;Li-8;Na-8;Si-70 & Cluster 2 avg & \\
\hline 28 & B-14;Li-8;Na-8;Si-70 & Cluster 2 avg & \\
\hline 29 & B-14;Li-8;Na-8;Si-70 & Cluster 2 avg & \\
\hline 30 & B-14;Li-8;Na-8;Si-70 & Cluster 2 avg & \\
\hline 31 & B-14;Li-8;Na-8;Si-70 & Cluster 2 avg & \\
\hline 32 & B-14;Li-8;Na-8;Si-70 & Cluster 2 avg & \\
\hline 33 & B-14;Li-8;Na-8;Si-70 & Cluster 2 avg & \\
\hline 34 & B-14;Li-8;Na-8;Si-70 & Cluster 2 avg & \\
\hline 35 & B-14;Li-8;Na-8;Si-70 & Cluster 2 avg & \\
\hline 36 & B-14;Li-8;Na-8;Si-70 & Cluster 2 avg & \\
\hline 37 & B-14;Li-8;Na-8;Si-70 & Cluster 2 avg & \\
\hline 38 & B-14;Li-8;Na-8;Si-70 & Cluster 2 avg & \\
\hline 39 & B-14;Li-8;Na-8;Si-70 & Cluster 2 avg & \\
\hline 40 & B-14;Li-8;Na-8;Si-70 & Cluster 2 avg & \\
\hline
\end{tabular}




\begin{tabular}{|c|c|c|c|}
\hline 41 & B-14;Li-8;Na-8;Si-70 & Cluster 2 avg & lowv \\
\hline 42 & B-14;Li-8;Na-8;Si-70 & Cluster 2 avg & lowv \\
\hline 43 & B-14;Li-8;Na-8;Si-70 & Cluster 2 avg & lowv \\
\hline 44 & B-14;Li-8;Na-8;Si-70 & Cluster 2 avg & lowv \\
\hline 45 & B-14;Li-8;Na-8;Si-70 & Cluster 2 avg & lowv Neph \\
\hline 46 & B-14;Li-8;Na-8;Si-70 & Cluster 2 avg & lowv Neph \\
\hline 47 & B-14;Li-8;Na-8;Si-70 & Cluster 2 avg & TL lowv Neph \\
\hline 48 & B-14;Li-8;Na-8;Si-70 & Cluster 2 avg & TL lowv Neph \\
\hline 49 & B-14;Li-8;Na-8;Si-70 & Cluster 2 avg & TL lowv Neph \\
\hline 50 & B-14;Li-8;Na-8;Si-70 & Cluster 2 avg & TL lowv Neph \\
\hline 25 & B-18;Li-8;Na-8;Si-66 & Cluster 2 avg & Homg \\
\hline 26 & B-18;Li-8;Na-8;Si-66 & Cluster 2 avg & \\
\hline 27 & B-18;Li-8;Na-8;Si-66 & Cluster 2 avg & \\
\hline 28 & B-18;Li-8;Na-8;Si-66 & Cluster 2 avg & \\
\hline 29 & B-18;Li-8;Na-8;Si-66 & Cluster 2 avg & \\
\hline 30 & B-18;Li-8;Na-8;Si-66 & Cluster 2 avg & lowv \\
\hline 31 & B-18;Li-8;Na-8;Si-66 & Cluster 2 avg & lowv \\
\hline 32 & B-18;Li-8;Na-8;Si-66 & Cluster 2 avg & lowv \\
\hline 33 & B-18;Li-8;Na-8;Si-66 & Cluster 2 avg & lowv \\
\hline 34 & B-18;Li-8;Na-8;Si-66 & Cluster 2 avg & lowv \\
\hline 35 & B-18;Li-8;Na-8;Si-66 & Cluster 2 avg & lowv \\
\hline 36 & B-18;Li-8;Na-8;Si-66 & Cluster 2 avg & lowv \\
\hline 37 & B-18;Li-8;Na-8;Si-66 & Cluster 2 avg & lowv \\
\hline 38 & B-18;Li-8;Na-8;Si-66 & Cluster 2 avg & lowv \\
\hline 39 & B-18;Li-8;Na-8;Si-66 & Cluster 2 avg & lowv \\
\hline 40 & B-18;Li-8;Na-8;Si-66 & Cluster 2 avg & lowv \\
\hline 41 & B-18;Li-8;Na-8;Si-66 & Cluster 2 avg & lowv \\
\hline 42 & B-18;Li-8;Na-8;Si-66 & Cluster 2 avg & lowv \\
\hline 43 & B-18;Li-8;Na-8;Si-66 & Cluster 2 avg & lowv Neph \\
\hline 44 & B-18;Li-8;Na-8;Si-66 & Cluster 2 avg & lowv Neph \\
\hline 45 & B-18;Li-8;Na-8;Si-66 & Cluster 2 avg & lowv Neph \\
\hline 46 & B-18;Li-8;Na-8;Si-66 & Cluster 2 avg & lowv Neph \\
\hline 47 & B-18;Li-8;Na-8;Si-66 & Cluster 2 avg & TL lowv Neph \\
\hline 48 & B-18;Li-8;Na-8;Si-66 & Cluster 2 avg & TL lowv Neph \\
\hline 49 & B-18;Li-8;Na-8;Si-66 & Cluster 2 avg & TL lowv Neph \\
\hline 50 & B-18;Li-8;Na-8;Si-66 & Cluster 2 avg & TL lowv Neph \\
\hline 25 & B-8;Li-8;Na-3;Si-81 & Cluster 4 avg & highv Homg hFrit \\
\hline 26 & B-8;Li-8;Na-3;Si-81 & Cluster 4 avg & highv Homg \\
\hline 27 & B-8;Li-8;Na-3;Si-81 & Cluster 4 avg & highv Homg \\
\hline 28 & B-8;Li-8;Na-3;Si-81 & Cluster 4 avg & highv \\
\hline 29 & B-8;Li-8;Na-3;Si-81 & Cluster 4 avg & highv \\
\hline 30 & B-8;Li-8;Na-3;Si-81 & Cluster 4 avg & highv \\
\hline 31 & B-8;Li-8;Na-3;Si-81 & Cluster 4 avg & \\
\hline 32 & B-8;Li-8;Na-3;Si-81 & Cluster 4 avg & \\
\hline 33 & B-8;Li-8;Na-3;Si-81 & Cluster 4 avg & \\
\hline 34 & B-8;Li-8;Na-3;Si-81 & Cluster 4 avg & \\
\hline 35 & B-8;Li-8;Na-3;Si-81 & Cluster 4 avg & \\
\hline 36 & B-8;Li-8;Na-3;Si-81 & Cluster 4 avg & \\
\hline
\end{tabular}




\begin{tabular}{|c|c|c|c|}
\hline 37 & B-8;Li-8;Na-3;Si-81 & Cluster 4 avg & \\
\hline 38 & B-8;Li-8;Na-3;Si-81 & Cluster 4 avg & \\
\hline 39 & B-8;Li-8;Na-3;Si-81 & Cluster 4 avg & \\
\hline 40 & B-8;Li-8;Na-3;Si-81 & Cluster 4 avg & \\
\hline 41 & B-8;Li-8;Na-3;Si-81 & Cluster 4 avg & \\
\hline 42 & B-8;Li-8;Na-3;Si-81 & Cluster 4 avg & \\
\hline 43 & B-8;Li-8;Na-3;Si-81 & Cluster 4 avg & $\mathrm{TL}$ \\
\hline 44 & B-8;Li-8;Na-3;Si-81 & Cluster 4 avg & $\mathrm{TL}$ \\
\hline 45 & B-8;Li-8;Na-3;Si-81 & Cluster 4 avg & $\mathrm{TL}$ \\
\hline 46 & B-8;Li-8;Na-3;Si-81 & Cluster 4 avg & TL \\
\hline 47 & B-8;Li-8;Na-3;Si-81 & Cluster 4 avg & $\mathrm{TL}$ \\
\hline 48 & B-8;Li-8;Na-3;Si-81 & Cluster 4 avg & TL \\
\hline 49 & B-8;Li-8;Na-3;Si-81 & Cluster 4 avg & TL \\
\hline 50 & B-8;Li-8;Na-3;Si-81 & Cluster 4 avg & $\mathrm{TL}$ \\
\hline 25 & B-8;Li-8;Na-8;Si-76 & Cluster 4 avg & Homg hFrit \\
\hline 26 & B-8;Li-8;Na-8;Si-76 & Cluster 4 avg & Homg \\
\hline 27 & B-8;Li-8;Na-8;Si-76 & Cluster 4 avg & Homg \\
\hline 28 & B-8;Li-8;Na-8;Si-76 & Cluster 4 avg & \\
\hline 29 & B-8;Li-8;Na-8;Si-76 & Cluster 4 avg & \\
\hline 30 & B-8;Li-8;Na-8;Si-76 & Cluster 4 avg & \\
\hline 31 & B-8;Li-8;Na-8;Si-76 & Cluster 4 avg & \\
\hline 32 & B-8;Li-8;Na-8;Si-76 & Cluster 4 avg & \\
\hline 33 & B-8;Li-8;Na-8;Si-76 & Cluster 4 avg & \\
\hline 34 & B-8;Li-8;Na-8;Si-76 & Cluster 4 avg & \\
\hline 35 & B-8;Li-8;Na-8;Si-76 & Cluster 4 avg & \\
\hline 36 & B-8;Li-8;Na-8;Si-76 & Cluster 4 avg & \\
\hline 37 & B-8;Li-8;Na-8;Si-76 & Cluster 4 avg & \\
\hline 38 & B-8;Li-8;Na-8;Si-76 & Cluster 4 avg & \\
\hline 39 & B-8;Li-8;Na-8;Si-76 & Cluster 4 avg & \\
\hline 40 & B-8;Li-8;Na-8;Si-76 & Cluster 4 avg & \\
\hline 41 & B-8;Li-8;Na-8;Si-76 & Cluster 4 avg & \\
\hline 42 & B-8;Li-8;Na-8;Si-76 & Cluster 4 avg & \\
\hline 43 & B-8;Li-8;Na-8;Si-76 & Cluster 4 avg & lowv \\
\hline 44 & B-8;Li-8;Na-8;Si-76 & Cluster 4 avg & lowv \\
\hline 45 & B-8;Li-8;Na-8;Si-76 & Cluster 4 avg & lowv \\
\hline 46 & B-8;Li-8;Na-8;Si-76 & Cluster 4 avg & lowv \\
\hline 47 & B-8;Li-8;Na-8;Si-76 & Cluster 4 avg & lowv \\
\hline 48 & B-8;Li-8;Na-8;Si-76 & Cluster 4 avg & lowv \\
\hline 49 & B-8;Li-8;Na-8;Si-76 & Cluster 4 avg & TL lowv \\
\hline 50 & B-8;Li-8;Na-8;Si-76 & Cluster 4 avg & TL lowv \\
\hline 25 & B-8;Li-8;Na-12;Si-72 & Cluster 4 avg & Homg R2O hFrit \\
\hline 26 & B-8;Li-8;Na-12;Si-72 & Cluster 4 avg & Homg R2O \\
\hline 27 & B-8;Li-8;Na-12;Si-72 & Cluster 4 avg & Homg R2O \\
\hline 28 & B-8;Li-8;Na-12;Si-72 & Cluster 4 avg & $\mathrm{R} 2 \mathrm{O}$ \\
\hline 29 & B-8;Li-8;Na-12;Si-72 & Cluster 4 avg & \\
\hline 30 & B-8;Li-8;Na-12;Si-72 & Cluster 4 avg & \\
\hline 31 & B-8;Li-8;Na-12;Si-72 & Cluster 4 avg & \\
\hline 32 & B-8;Li-8;Na-12;Si-72 & Cluster 4 avg & \\
\hline
\end{tabular}




\begin{tabular}{|c|c|c|c|}
\hline 33 & B-8;Li-8;Na-12;Si-72 & Cluster 4 avg & lowv \\
\hline 34 & B-8;Li-8;Na-12;Si-72 & Cluster 4 avg & lowv \\
\hline 35 & B-8;Li-8;Na-12;Si-72 & Cluster 4 avg & lowv \\
\hline 36 & B-8;Li-8;Na-12;Si-72 & Cluster 4 avg & lowv \\
\hline 37 & B-8;Li-8;Na-12;Si-72 & Cluster 4 avg & lowv \\
\hline 38 & B-8;Li-8;Na-12;Si-72 & Cluster 4 avg & lowv \\
\hline 39 & B-8;Li-8;Na-12;Si-72 & Cluster 4 avg & lowv \\
\hline 40 & B-8;Li-8;Na-12;Si-72 & Cluster 4 avg & lowv \\
\hline 41 & B-8;Li-8;Na-12;Si-72 & Cluster 4 avg & lowv \\
\hline 42 & B-8;Li-8;Na-12;Si-72 & Cluster 4 avg & lowv \\
\hline 43 & B-8;Li-8;Na-12;Si-72 & Cluster 4 avg & lowv \\
\hline 44 & B-8;Li-8;Na-12;Si-72 & Cluster 4 avg & lowv \\
\hline 45 & B-8;Li-8;Na-12;Si-72 & Cluster 4 avg & lowv \\
\hline 46 & B-8;Li- $8 ; \mathrm{Na}-12 ; \mathrm{Si}-72$ & Cluster 4 avg & lowv \\
\hline 47 & B-8;Li-8;Na-12;Si-72 & Cluster 4 avg & lowv \\
\hline 48 & B-8;Li-8;Na-12;Si-72 & Cluster 4 avg & lowv Neph \\
\hline 49 & B-8;Li-8;Na-12;Si-72 & Cluster 4 avg & lowv Neph \\
\hline 50 & B-8;Li-8;Na-12;Si-72 & Cluster 4 avg & lowv Neph \\
\hline 25 & B-14;Li-8;Na-8;Si-70 & Cluster 4 avg & Homg hFrit \\
\hline 26 & B-14;Li-8;Na-8;Si-70 & Cluster 4 avg & Homg \\
\hline 27 & B-14;Li-8;Na-8;Si-70 & Cluster 4 avg & Homg \\
\hline 28 & B-14;Li-8;Na-8;Si-70 & Cluster 4 avg & \\
\hline 29 & B-14;Li-8;Na-8;Si-70 & Cluster 4 avg & \\
\hline 30 & B-14;Li-8;Na-8;Si-70 & Cluster 4 avg & \\
\hline 31 & B-14;Li-8;Na-8;Si-70 & Cluster 4 avg & \\
\hline 32 & B-14;Li-8;Na-8;Si-70 & Cluster 4 avg & \\
\hline 33 & B-14;Li-8;Na-8;Si-70 & Cluster 4 avg & lowv \\
\hline 34 & B-14;Li-8;Na-8;Si-70 & Cluster 4 avg & lowv \\
\hline 35 & B-14;Li-8;Na-8;Si-70 & Cluster 4 avg & lowv \\
\hline 36 & B-14;Li-8;Na-8;Si-70 & Cluster 4 avg & lowv \\
\hline 37 & B-14;Li-8;Na-8;Si-70 & Cluster 4 avg & lowv \\
\hline 38 & B-14;Li-8;Na-8;Si-70 & Cluster 4 avg & lowv \\
\hline 39 & B-14;Li-8;Na-8;Si-70 & Cluster 4 avg & lowv \\
\hline 40 & B-14;Li-8;Na-8;Si-70 & Cluster 4 avg & lowv \\
\hline 41 & B-14;Li-8;Na-8;Si-70 & Cluster 4 avg & lowv \\
\hline 42 & B-14;Li-8;Na-8;Si-70 & Cluster 4 avg & lowv \\
\hline 43 & B-14;Li-8;Na-8;Si-70 & Cluster 4 avg & lowv \\
\hline 44 & B-14;Li-8;Na-8;Si-70 & Cluster 4 avg & lowv \\
\hline 45 & B-14;Li-8;Na-8;Si-70 & Cluster 4 avg & lowv \\
\hline 46 & B-14;Li-8;Na-8;Si-70 & Cluster 4 avg & lowv \\
\hline 47 & B-14;Li-8;Na-8;Si-70 & Cluster 4 avg & lowv \\
\hline 48 & B-14;Li-8;Na-8;Si-70 & Cluster 4 avg & TL lowv \\
\hline 49 & B-14;Li-8;Na-8;Si-70 & Cluster 4 avg & TL lowv \\
\hline 50 & B-14;Li-8;Na-8;Si-70 & Cluster 4 avg & TL lowv \\
\hline 25 & B-18;Li-8;Na-8;Si-66 & Cluster 4 avg & lowv Homg \\
\hline 26 & B-18;Li-8;Na-8;Si-66 & Cluster 4 avg & lowv Homg \\
\hline 27 & B-18;Li-8;Na-8;Si-66 & Cluster 4 avg & lowv Homg \\
\hline 28 & B-18;Li-8;Na-8;Si-66 & Cluster 4 avg & lowv \\
\hline
\end{tabular}




\begin{tabular}{|c|c|c|c|}
\hline 29 & B-18;Li-8;Na-8;Si-66 & Cluster 4 avg & lowv \\
\hline 30 & B-18;Li-8;Na-8;Si-66 & Cluster 4 avg & lowv \\
\hline 31 & B-18;Li-8;Na-8;Si-66 & Cluster 4 avg & lowv \\
\hline 32 & B-18;Li-8;Na-8;Si-66 & Cluster 4 avg & lowv \\
\hline 33 & B-18;Li-8;Na-8;Si-66 & Cluster 4 avg & lowv \\
\hline 34 & B-18;Li-8;Na-8;Si-66 & Cluster 4 avg & lowv \\
\hline 35 & B-18;Li-8;Na-8;Si-66 & Cluster 4 avg & lowv \\
\hline 36 & B-18;Li-8;Na-8;Si-66 & Cluster 4 avg & lowv \\
\hline 37 & B-18;Li-8;Na-8;Si-66 & Cluster 4 avg & lowv \\
\hline 38 & B-18;Li-8;Na-8;Si-66 & Cluster 4 avg & lowv \\
\hline 39 & B-18;Li-8;Na-8;Si-66 & Cluster 4 avg & lowv \\
\hline 40 & B-18;Li-8;Na-8;Si-66 & Cluster 4 avg & lowv \\
\hline 41 & B-18;Li-8;Na-8;Si-66 & Cluster 4 avg & lowv \\
\hline 42 & B-18;Li-8;Na-8;Si-66 & Cluster 4 avg & lowv \\
\hline 43 & B-18;Li-8;Na-8;Si-66 & Cluster 4 avg & lowv \\
\hline 44 & B-18;Li-8;Na-8;Si-66 & Cluster 4 avg & lowv \\
\hline 45 & B-18;Li-8;Na-8;Si-66 & Cluster 4 avg & lowv \\
\hline 46 & B-18;Li-8;Na-8;Si-66 & Cluster 4 avg & lowv \\
\hline 47 & B-18;Li-8;Na-8;Si-66 & Cluster 4 avg & lowv \\
\hline 48 & B-18;Li-8;Na-8;Si-66 & Cluster 4 avg & TL lowv \\
\hline 49 & B-18;Li-8;Na-8;Si-66 & Cluster 4 avg & TL lowv Neph \\
\hline 50 & B-18;Li-8;Na-8;Si-66 & Cluster 4 avg & TL lowv Neph \\
\hline
\end{tabular}


SRNS-STI-2008-00081

Revision 0

This page intentionally left blank. 


\section{Distribution:}

C.J. Bannochie, 773-42A

A.B. Barnes, 999-W

D.R. Best, 786-5A

J.M. Bricker, 704-27S

D.A. Crowley, 999-W

B.A. Davis, 704-27S

T.B. Edwards, 999-W

T.L. Fellinger, 704-26S

S.D. Fink, 773-A

K.M. Fox, 999-W

C.W. Gardner, 773-A

B.J. Giddings, 786-5A

J.M. Gillam, 766-H

J.C. Griffin, 773-A

B.A. Hamm, 766-H

C.C. Herman, 999-W

P. J. Hill, 766-H

J.F. Iaukea, 704-30S

D.P. Lambert, 999-W

D.D. Larsen, 776-H
M.T. Keefer, 766-H

J.E. Marra, 773-A

D.J. McCabe, 773-42A

R.T. McNew, 704-27S

D.H. Miller, 999-W

T.A. Nance, 773-42A

J.E. Occhipinti, 704-S

D.K. Peeler, 999-W

B.R. Pickenheim, 999-W

J.A. Pike, 773-42A

T.M. Punch, 766-H

F.C. Raszewski, 999-w

J.W. Ray, 704-S

H.B. Shah, 766-H

M.E. Smith, 704-30S

M.E. Stone, 999-W

P.C. Suggs, 704-S

W.R. Wilmarth, 773-42A

A.L. Youchak, 999-W 